\title{
Solar-thermal production of graphitic carbon and hydrogen via methane decomposition
}

\author{
Mostafa Abuseada ${ }^{1}$, Chuyu Wei ${ }^{1}$, \\ R. Mitchell Spearrin ${ }^{1}$, Timothy S. Fisher ${ }^{1 *}$ \\ ${ }^{1}$ Mechanical \& Aerospace Engineering Department \\ University of California Los Angeles \\ and California NanoSystems Institute \\ 420 Westwood Plaza, Los Angeles, CA 90095 USA
}

*To whom correspondence should be addressed; E-mail: tsfisher@ucla.edu.

Summary: A method to decompose methane into graphite and hydrogen using direct, concentrated solar irradiation of a porous substrate, enabling facile production of critical green-economy solid and fuel with renewable energy.

This work reports a process in which concentrated irradiation from a simulated solar source converts methane to high-value graphitic carbon and hydrogen gas. Methane flows within a photo-thermal reactor through the pores of a thin substrate irradiated by several thousand suns at the focal peak. The methane decomposes primarily into hydrogen while depositing highly graphitic carbon that grows conformally over ligaments in the porous substrate. The localized solar heating of the porous substrate serves to capture the solid carbon into a readily extractable and useful form while maintaining active deposition site density with persistent catalytic activity. Results indicate a strong temperature dependence with high decomposition occurring in the central heating zone with concentration factors and temperatures above 1000 suns and 1300 $\mathrm{K}$, respectively. Even with a large flow area through regions of lower irradiation and temperature, methane conversion and hydrogen yields of approx. 70\% are achieved, and $58 \%$ of the inlet carbon is captured in graphitic form. 


\section{Introduction}

Current industrial processes for power, fuel, and commodity production are responsible for massive, ongoing $\mathrm{CO}_{2}$ emissions that adversely affect the stability of Earth's climate with potentially disastrous consequences (1). Increased use of hydrogen as a fuel and chemical building block promises to reduce $\mathrm{CO}_{2}$ emissions in critical sectors, but modern hydrogen production technologies also involve high greenhouse gas emissions. Specifically, steam methane reforming (SMR) typically relies on fossil-fuel combustion to derive heat and constitutes $95 \%$ of current hydrogen production (2) with substantial $\mathrm{CO}_{2}$ emissions. The entirety of the combustion heating would be avoided by utilizing a portion of the bountiful 75,000 terawatts of solar power reaching Earth's surface (3) to meet the growing demand for hydrogen (10 MT/yr in the US and growing). Clean hydrogen production that avoids combustion-derived heat generally offsets approximately $10 \mathrm{~kg}$ of $\mathrm{CO}_{2}$ emissions per $\mathrm{kg} \mathrm{H}_{2}$ (4). The present work describes such a process that also produces high-value graphitic carbon.

SMR is the most cost-effective current hydrogen production process. Water electrolysis driven by solar energy is an emerging alternative, with potentially $30 \%$ solar-to-hydrogen efficiency but significantly higher production cost at present (5). Similar challenges exist for alternative solar-driven processes such as $\mathrm{CO}_{2} / \mathrm{H}_{2} \mathrm{O}$ dissociation (6). Solar methane dissociation stands out as a possible near-term alternative to SMR in starting with a useful carbon-containing fuel and ending with a carbon-free fuel as well as a potentially valuable carbon product, which is likely to be important in bringing operational costs to a competitive level $(2,7)$.

Thermal decomposition of $\mathrm{CH}_{4}$, also known as methane cracking or pyrolysis, is an endothermic reaction that breaks down $\mathrm{CH}_{4}$ into solid carbon (C) and $\mathrm{H}_{2}$ gas through the following global dissociation reaction (8):

$$
\mathrm{CH}_{4} \rightarrow \mathrm{C}+2 \mathrm{H}_{2} \quad\left(\Delta H^{o}=74.6 \mathrm{~kJ} / \mathrm{mol}\right)
$$

This reaction typically proceeds at temperatures above $1000 \mathrm{~K}$ and follows a more complex chemical kinetic pathway that includes several light and stable hydrocarbons, mainly acetylene, ethylene, and ethane, as intermediaries and minor products (9).

Solar-thermal pyrolysis of methane has been studied in prior work, most often to produce hydrogen and an amorphous solid, carbon black. Indirect solar heating in a tubular reactor has been demonstrated at a $50 \mathrm{~kW}$ pilot scale $(10,11)$, producing temperatures above $1600 \mathrm{~K}$ and hydrogen yields (i.e., the fraction of inlet elemental hydrogen that emerges as hydrogen gas product) up to $88 \%$, with lower yields of solid carbon black (less than 63\%). Other studies 
have attempted to achieve high overall decomposition rates by using volumetric absorption in suspended particle flows $(12,13)$ and packed beds $(14)$, with similar observations that substrate temperatures in the range of 1300 to $1600 \mathrm{~K}$ produce the highest hydrogen yields. However, all these studies produce predominantly carbon black, and issues such as solid obstruction and window deposition present practical challenges (15). Metal catalysts have been shown to decrease reaction temperatures to as low as $873 \mathrm{~K}$ and to produce small quantities of partially graphitized carbon nanostructures (16); however, common issues with metal catalysis related to cost, sustained activity, and post-process purification make such systems less amenable to methane decomposition at large scale (2).

Here, we present a new approach to solar-thermal methane pyrolysis that uniquely produces high surface-area, high-value graphitic carbon. The method involves a direct solar-thermal reactor with a locally heated region that mitigates the practical limitations of carbon deposition on the reactor walls and windows and allows photo-thermal catalytic effects that are not possible in indirect solar reactors. The solar-driven co-production of graphitic carbon with hydrogen provides a means to meet clean hydrogen demand as well as providing electrode materials for the rapidly growing Li-ion battery market (17) while reducing $\mathrm{CO}_{2}$ emissions associated with production processes of such materials.

\section{Methodology}

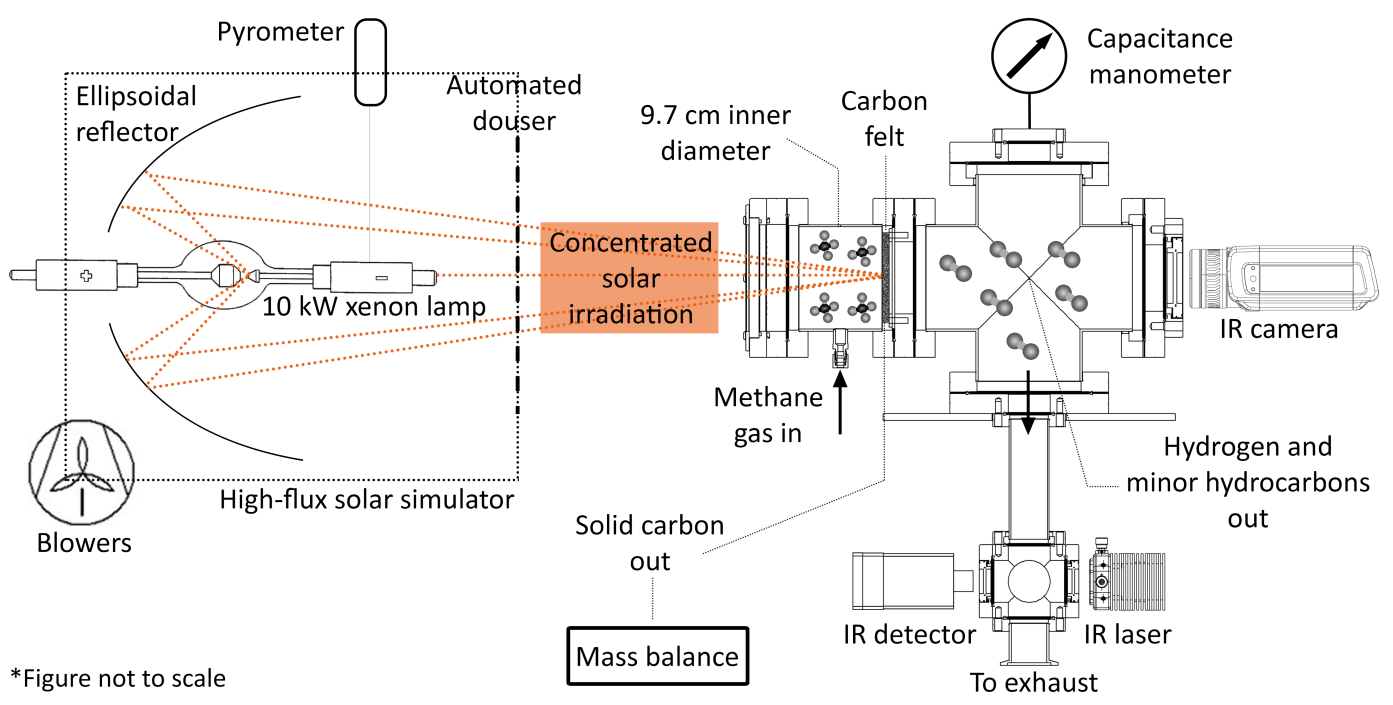

Figure 1: Overview of the solar methane decomposition experimental setup and process. 
An overview of the concentrated solar pyrolysis process is shown in Fig. 1. The radiative heat source in the experimental setup is a custom-built high-flux solar simulator (HFSS) consisting of a $10 \mathrm{~kW}_{\mathrm{e}}$ xenon short-arc lamp (Superior Quartz Products - SQP-SX100003), an ellipsoidal reflector, and a variable DC power supply with a current range of 100-200 A. This lamp type has been a common choice in prior work with simulated solar sources, as it closely resembles the AM 1.5 solar standard spectrum $(18,19)$. The HFSS produces controllable radiative intensities up to a peak of approximately 4500 suns $\left(1\right.$ sun $\left.=1 \mathrm{~kW} / \mathrm{m}^{2}\right)$ with a Lorentzian distribution at the focal plane and can produce maximum surface temperatures above $1500 \mathrm{~K}$. The controllable photonic output of the solar simulator enables the optimization of the decomposition of methane, and can reproduce natural variations of insolation (e.g., sunrise/sunset and clouds) for testing real-world scenarios (20) (see Supplementary Materials for additional information on the heat flux distribution and characterization). Uncertainty quantification for all measurements is provided in Supplemental Materials.

The reactor consists of a $10 \mathrm{~cm}$ diameter quartz window to transmit light and provisions for metered inlet gas flowing through a porous carbon felt substrate (FuelCellEarth C100). The felt is mounted on a reducing flange with a $6.9 \mathrm{~cm}$ diameter orifice placed at the HFSS focal plane and centered within a $9.7 \mathrm{~cm}$ diameter stainless steel cylinder (see Fig. 1). The reactor is supplemented with an automated monitoring and control system consisting of various mass flow controllers, a high-resolution infrared (IR) camera (FLIR A655sc) for spatial temperature measurements, capacitance manometers for pressure monitoring, relays, valves, and a PXI controller (National Instruments).

The carbon felt is comprised of polyacrylonitrile (PAN) fibers of nominally $10 \mu \mathrm{m}$ diameter, an overall felt diameter and thickness of $6.9 \mathrm{~cm}$ and $3.2 \mathrm{~mm}$, solid volume fraction of 0.048 , and an average separation between fibers of $40 \mu \mathrm{m}$ (see Supplementary Materials). By confining the reaction zone to the thin porous carbon felt that is directly irradiated, carbon product is trapped within the substrate, while the reactor walls and windows can remain relatively cold to mitigate unwanted decomposition and carbon deposition $(21,22)$. This approach also confines the solar irradiation and high temperatures to a small region, avoiding high overall reactor operating temperatures that increase heat losses (23). Moreover, active reaction site density for decomposition is high on the microfibrous substrate. Pre- and post-processed felt substrates were characterized by Raman spectroscopy, scanning electron microscopy, BET porosimetry, and x-ray diffractometry (see Supplementary Materials).

To enable real-time analysis of fuel conversion and chemical kinetics, methane (and other 
minor hydrocarbons) are quantified by in situ laser absorption spectroscopy downstream of the reaction zone. Exploiting recent advances in mid-IR photonics that enable spectral coverage of the fundamental $\mathrm{C}-\mathrm{H}$ stretch vibrational bands near $3 \mu \mathrm{m}$ with compact, room-temperature semi-conductor lasers $(24,25)$, various hydrocarbon species (e.g., $\left.\mathrm{C}_{2} \mathrm{H}_{2}, \mathrm{C}_{2} \mathrm{H}_{4}, \mathrm{C}_{2} \mathrm{H}_{6}\right)$ can be monitored on-line (i.e., with no fluid sampling required, $c f$., by mass spectrometry, see Supplementary Materials and Fig. S5]. The time-resolved nature of the spectroscopic measurements provides direct information about the chemical evolution of the decomposition process and provides for rapid comparison and optimization of process conditions (e.g., temperature, pressure, material, geometry). Additionally, the approach can be used to monitor trace products (e.g. $\mathrm{C}_{2} \mathrm{H}_{6}$ ) that were not possible to quantify in other studies (14). Fig. $2 \mathrm{a}$ shows the IR laser absorption spectroscopy experimental setup for monitoring $\mathrm{CH}_{4}, \mathrm{C}_{2} \mathrm{H}_{4}$, and $\mathrm{C}_{2} \mathrm{H}_{6}$.
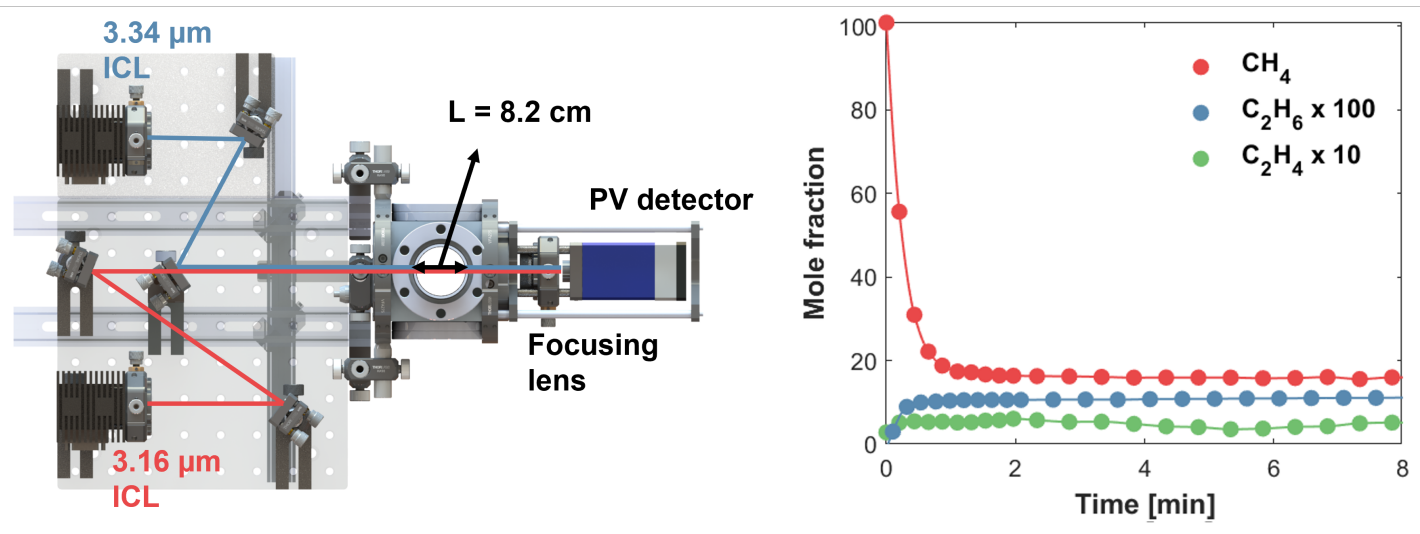

Figure 2: IR absorption spectroscopy monitoring experimental setup (left). Product mole fractions as a function of time (right). $\mathrm{CH}_{4}$ decomposition at $100 \mathrm{sccm}$ flow rate, 25 Torr pressure, $2.24 \mathrm{~kW}$ gross radiant power, and 20 min reaction period.

\section{Results}

Methane decomposition through the carbon felt was tested under a maximum central irradiance of 3400 suns (2.24 kW gross radiant power), with $99.999 \%$ pure methane inlet flowing at 100 sccm under an operating pressure of 25 Torr. The default test duration was 20 minutes, and Fig. $2 \mathrm{p}$ shows the resulting time-resolved quantitative measurements of methane $\left(\mathrm{CH}_{4}\right)$, ethylene $\left(\mathrm{C}_{2} \mathrm{H}_{4}\right)$, and ethane $\left(\mathrm{C}_{2} \mathrm{H}_{6}\right)$ in the product gas stream. When the solar irradiance (shown in Fig. 3a) instantaneously focuses on the porous substrate initially at room temperature, de- 

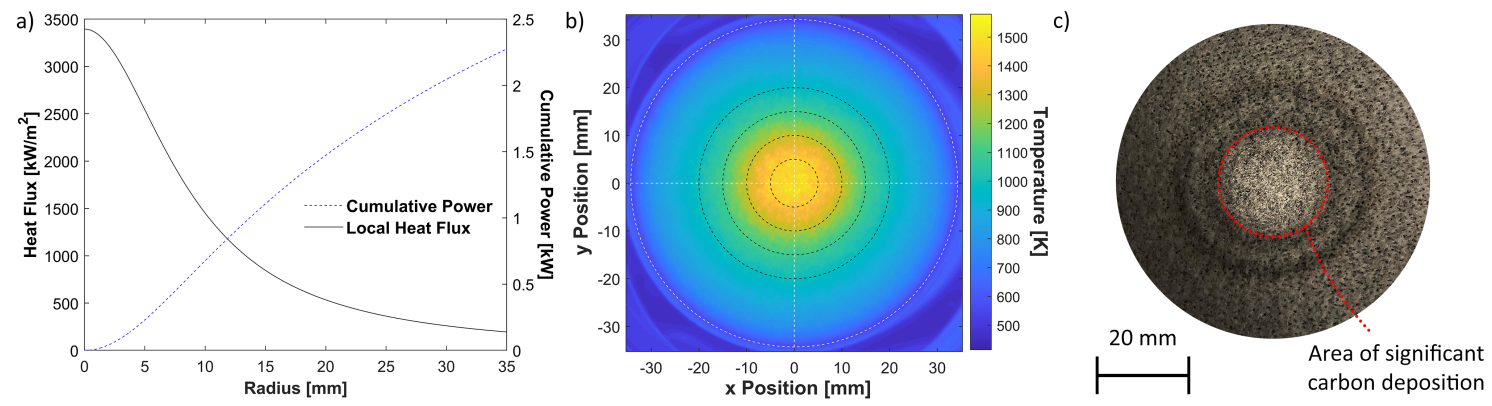

Figure 3: (a) Heat flux distribution and cumulative power as functions of radius at the focal plane, (b) temperature profile of the carbon felt's back surface during $\mathrm{CH}_{4}$ decomposition obtained using a high-resolution IR camera (centered black rings with $r=5,10,15$, and $20 \mathrm{~mm}$ illustrate distribution and angular uniformity), and (c) carbon felt with carbon deposition. $\mathrm{CH}_{4}$ decomposition at $100 \mathrm{sccm}$ flow rate, 25 Torr pressure, $2.24 \mathrm{~kW}$ gross radiant power, and 20 min reaction period.

composition rapidly decreases methane concentration in the product stream, yielding primarily hydrogen and solid carbon deposition. The transition from room temperature to steady-state operating conditions occurs within the first minute of insolation, after which the methane mole fraction stabilizes at 0.16 and temperatures within the carbon felt reach steady values (Fig. 33). Upon methane decomposition for 20 minutes, the weight of the carbon felt increased by 0.62 $\mathrm{g}$; the processed felt is shown in Fig. 3c with an indication of significant carbon deposition in a central circle. The amount of collected solid carbon on the felt substrate represents $58 \%$ of the available carbon in the inlet methane feed during the test.

IR temperature mapping (Fig. 3b) reveals a large temperature gradient in the substrate that is a consequence of the Lorentzian light source distribution (Fig. 33). This characteristic of the experimental setup allows us to study ranges of light intensity and temperatures in a single experiment. The central circular region ( $25 \mathrm{~mm}$ diameter) of the substrate produces temperatures well above $1000 \mathrm{~K}$, beyond which the substrate temperatures decrease markedly with increasing radius. The local heat flux at the edge of this central region $(r=12.5 \mathrm{~mm})$ is 1100 suns, and the area-weighted average from the center to $r=12.5 \mathrm{~mm}$ is 1800 suns. From a practical standpoint, these levels of temperature and solar concentration, while relatively high, have been shown to be readily achievable in large-scale field demonstrations $(26,27)$.

To assess overall methane-to-hydrogen conversion efficacy, we use a basic definition of overall hydrogen yield in which, ideally (see Eq. 1), each reactant methane molecule produces 
two hydrogen product molecules:

$$
Y_{H_{2}, t o t}=\frac{\dot{n}_{H_{2, \text { out }}}}{2 \dot{n}_{C H_{4, \text { in }}}}
$$

where $\dot{n}_{i}$ denotes the molar flow rate of species $i$. The hydrogen molar flow rate is determined from the on-line measurements of light hydrocarbons in the product stream (see Fig. 2) combined with supplemental mass spectroscopy and related analysis (see Supplementary Materials and Fig. S6 . With the methane mole fraction $\left(x_{\mathrm{CH}_{4}}\right)$ at 0.16 and the vast majority of the hydrocarbon product flow as $\mathrm{CH}_{4}$, the overall hydrogen yield for the conditions of Fig. 2] is $69 \%$ (see Supplementary Materials and Eq. S12.

Because the reaction pathways also yield minor hydrocarbon byproducts $\left(\mathrm{C}_{2} \mathrm{H}_{2}, \mathrm{C}_{2} \mathrm{H}_{4}\right.$, and $\mathrm{C}_{2} \mathrm{H}_{6}$ ), detection of these species enables a more complete understanding of the photothermal catalysis efficacy and provides for process optimization. Fig. S6 includes real-time results from a calibrated on-line mass spectrometer. A detailed description of the reaction pathways to form minor species with chemical kinetics modeling is included in Supplementary Materials, with a calculated methane conversion of $73 \%$. From a mass balance analysis with the foregoing yields, the expected carbon weight and yield are $0.627 \mathrm{~g}$ and $58.3 \%$ which when compared to the $58 \%$ measured capture indicates that virtually all carbon deposition occurs on the carbon felt. Thus, the difference between the methane conversion and solid carbon deposition percentages is a consequence of minor hydrocarbons gas (mainly $\mathrm{C}_{2} \mathrm{H}_{2}$ ).

The methane conversion remains stable for twenty minutes during significant accumulation of solid carbon on the substrate. The product-stream and mass measurements are consistent with post-processed SEM images of the felt in Fig. 4 and Fig. S9. Comparing the original fibers to the processed fibers (Fig. 4a), the carbon fiber thickness at the center of the reaction zone increases significantly from 10 to $90 \mu \mathrm{m}$ in the region with a maximum temperature of approx. $1500 \mathrm{~K}$. The original core of the fiber and the deposited carbon layers are clearly apparent in Fig. 4p, where the image suggests a less dense and possibly microporous structure as further verified through $\mathrm{N}_{2}$ adsorption experiments (see Supplementary Materials). The specific surface area from the BET method indicates a 5-fold increase in a sample taken from the central region ( $r \approx 0-5 \mathrm{~mm}$ ) as compared to the original carbon felt. If the carbon product and original fibers were fully dense, the specific surface area should have instead decreased by a factor of 7-10 based on the cylindrical surface area of the fibers (see Supplementary Materials for methods and additional results). The production of a microporous solid product is expected to be useful in electrochemical energy storage applications. 

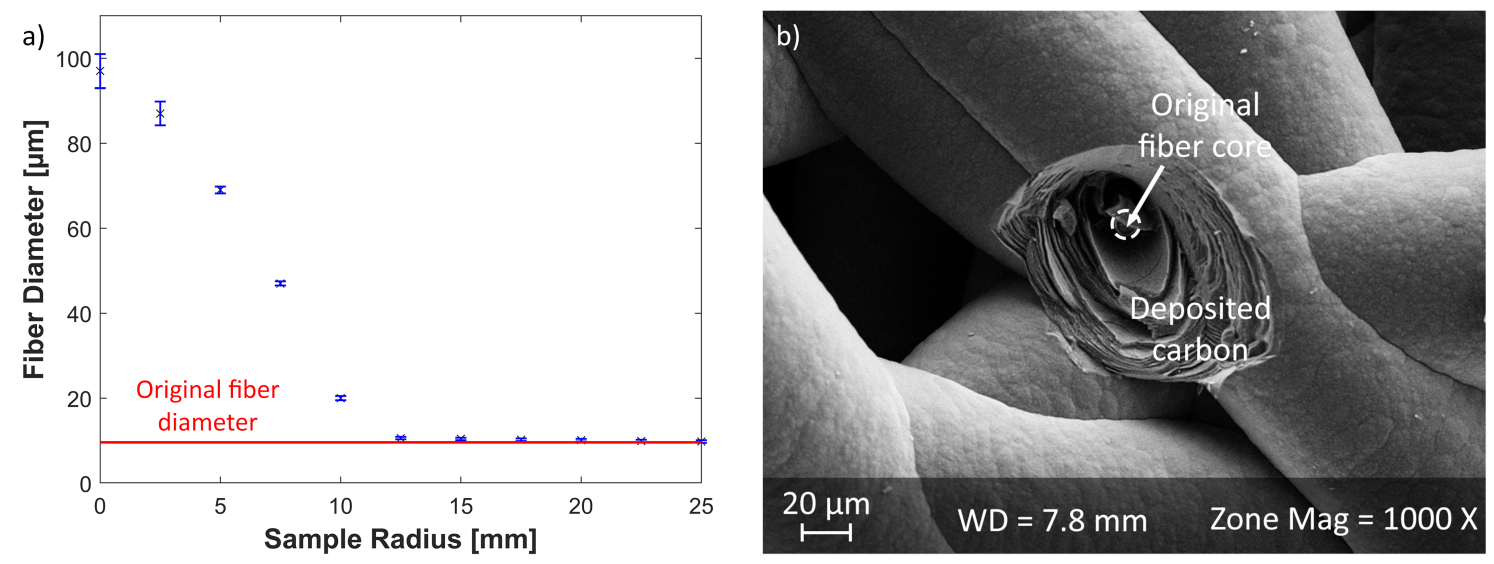

Figure 4: Morphology analysis on carbon felt product showing (a) fiber diameter as a function of radial distance from the center as compared to the original carbon felt diameter, and (b) SEM image at the center of the carbon felt demonstrating the nature and amount of carbon deposition. $\mathrm{CH}_{4}$ decomposition at $100 \mathrm{sccm}$ flow rate, 25 Torr pressure, $2.24 \mathrm{~kW}$ gross radiant power, and 20 min reaction period.

The thickness of the conformal graphitic deposition depends strongly on radial position, as shown in Fig. 4 a, with the majority of deposition in the hot central region $(r \leq 10 \mathrm{~mm})$. To assess carbon quality, Raman spectra of the carbon cloth before and after deposition were obtained as shown in Fig. 5a. The presence of a distinct 2D peak and low D/G peak ratio in the deposited carbon clearly indicates the formation of a high-quality graphitic carbon at the center of the substrate as well as at $r=5 \mathrm{~mm}$. Conversely, the original carbon felt's Raman spectrum lacks these features. The formation of a layered graphitic structure is also apparent in the SEM image of Fig. $4 \mathrm{~b}$, which shows a fractured cross section with deposited ring-like layers surrounding the original microfiber core. The crystalline structure of the carbon within the central region was evaluated by x-ray diffraction and compared to the original carbon felt, as shown in the spectra of Fig. $5 \mathrm{~b}$. The average interplanar distances, $d_{002}$, determined from the (002) reflection position and Bragg's law are 3.56 and $3.42 \AA$ for the original carbon felt and the carbon product, respectively. The latter spacing is consistent with turbostratic graphite (28) and clearly indicative of high graphitization. Additionally, the average crystallite sizes along the c-axis as determined from the Scherrer equation are 2.07 and $9.69 \mathrm{~nm}$ for the original felt and product, respectively (see Supplementary Materials for further analysis). 

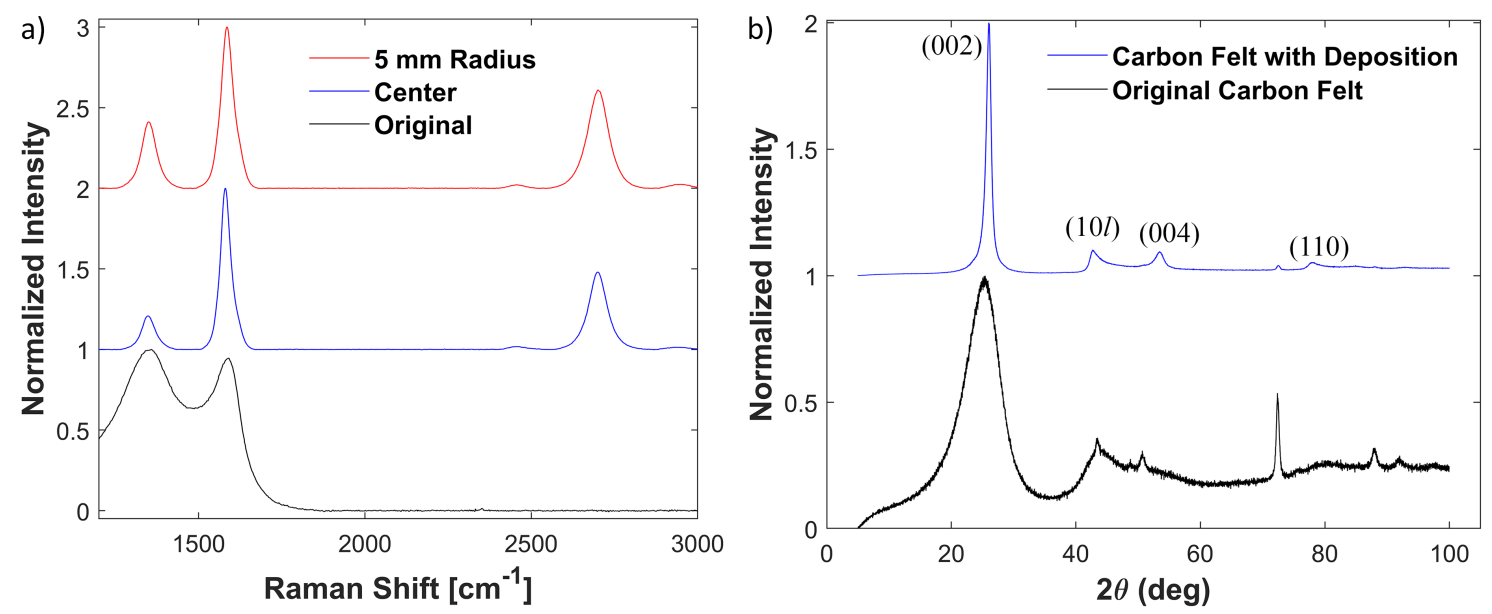

Figure 5: Structural analysis on carbon felt product showing (a) Raman spectra of the carbon product at the center and $5 \mathrm{~mm}$ radial distance as compared to the original carbon felt, and (b) XRD spectra of the carbon product at the central region as compared to the original carbon felt. $\mathrm{CH}_{4}$ decomposition at $100 \mathrm{sccm}$ flow rate, 25 Torr pressure, $2.24 \mathrm{~kW}$ gross radiant power, and 20 min reaction period.

\section{Discussion}

A significant challenge with many thermal energy systems, including solar-thermal fuels and electric power production, is their slow startup time response of an hour or more $(29, p 292)$. In contrast, the process reported here shows a much faster time response of approx. 1 min to reach steady-state thermochemical conditions (see Fig. 2b). The fast response is primarily the result of the low thermal mass of the carbon felt, which serves as both efficient light absorber and catalytic substrate. This feature enables the possibility of high levels of process control under realistic field insolance conditions. To highlight this attribute further, we cycled the light source in an on/off manner with a period of 2 min under constant methane flow. The resulting video of the product stream IR absorption monitoring demonstrates the repeatability of both the fast response and the return to high methane conversion levels (see Supplementary Materials, Movie S1).

The growth rate of conformal graphitic films on the fiber substrate appears to be exceptionally high. For comparison, a recent report (30) of graphite-like films grown by chemical vapor deposition (CVD) on nickel, involving carbon dissolution in nickel followed by surface precipitation upon cooling, indicated an effective growth rate of $1 \mu \mathrm{m} / \mathrm{hr}$ with a maximum thickness of $500 \mathrm{~nm}$. An earlier report (31) of hot-wall thermal CVD by methane pyrolysis at temperatures, 
pressures, and flow rates similar to those in the present study reported a maximum graphitic mass deposition rate of $20 \mathrm{mg} / \mathrm{hr}$ on a large graphite rod substrate, which corresponds to a film growth rate of approx. $5.7 \mu \mathrm{m} / \mathrm{hr}$. In contrast, the growth rate observed in the present experiments is much higher. On a mass basis, we observe mass deposition rates of approx. 1850 $\mathrm{mg} / \mathrm{hr}$ (see Supplementary Materials), which is 93 times higher than the maximum reported in ref. (31) for a system with a much larger reaction zone. In terms of film growth rates, our results indicate a radial fiber growth rate of $135 \mu \mathrm{m} / \mathrm{hr}$ in the center of the felt substrate, which is 25 times higher.

Prior work (16) on solar methane pyrolysis with carbon black production under a maximum irradiance of 3000 suns reported a carbon deposition rate on a catalyst mass basis of $2.83 \mathrm{mg} / \mathrm{g}_{\text {cat }}$ per minute. Here, the graphitic deposition rate of $28.2 \mathrm{mg} / \mathrm{g}_{\text {cat }}$ per minute is ten times higher based on the starting carbon felt mass of $1.10 \mathrm{~g}_{\text {cat }}$. We also emphasize that the centrally heated portion of the circular felt substrate is only approx. $10 \%$ of the felt's total area. Therefore, the high carbon deposition and hydrogen production rates in the present experiments, while already high, should be readily amenable to further increases by, for example, expanding the area of high heat flux via optics and/or decreasing the size of flow area to minimize methane bypass through the lower-temperature annulus.

Another distinguishing attribute of the present results is the short residence time of gases in the reaction zone that nevertheless produces high graphitic growth rates and hydrogen yields. Here, the estimated reaction residence time is $0.054 \mathrm{sec}$ (see Supplementary Materials), whereas it varied from 3 to $26 \mathrm{sec}$ in the prior thermal CVD experiments (31). A previous study of solar methane pyrolysis with indirect irradiation (10) at slightly higher temperature $(1600 \mathrm{~K})$ and residence time $(0.07 \mathrm{sec})$ than the present work reported methane conversion of $72 \%$ and a substantially lower hydrogen yield of $57 \%$ due to incomplete dissociation. In our study, despite graphitic carbon growth focused at the center of the substrate, we observe relatively high hydrogen yields from the bulk flow, much of which passes through substrate regions where little carbon is captured. This observation likely results from a kinetically limited process wherein the step-wise reduction in $\mathrm{H}: \mathrm{C}$ ratio via hydrogen abstraction does not reach equilibrium or solid carbon formation within the residence time. This explanation is consistent with a relatively lower carbon yield compared to hydrogen yield. In effect, the cooler temperatures on annular regions of the substrate result in a vapor sheath and minimal wall deposition. Furthermore, based on the magnitudes of measured surface temperatures away from the central core, decomposition rates are expected to be quite slow, suggesting lower product yields in a kineti- 
cally limited process. The totality of the foregoing distinctions related to deposition rates, yields and residence times suggests a strong photothermal catalytic effect from the concentrated light source that is enhancing the chemical kinetic rates. Recent insights into hot-carrier plasmonic photocatalytic decomposition of ammonia (32) may apply to the present methane decomposition, where in this case the intermediate deposition of graphene domains could serve as plasmonic centers (33); however, further controlled studies of such behavior would be necessary to assess this hypothesis.

The performance of the methane decomposition process has been further examined through a long-duration test lasting for $120 \mathrm{~min}$, under a flow rate of $100 \mathrm{sccm}$, pressure of 25 Torr, and gross radiant power of $2.24 \mathrm{~kW}$. The net carbon product collected on the original felt was measured to be $2.26 \mathrm{~g}$, which is more than twice the starting mass of the original carbon felt (i.e., $2.05 \mathrm{~g} / \mathrm{g}_{\text {cat }}$ ). If only the area with active carbon deposition is considered ( $25 \mathrm{~mm}$ diameter, see Fig. 4a), the net carbon product collected increases to $15.5 \mathrm{~g} / \mathrm{g}_{\text {cat }}$. These results compare well to a net carbon production value of $0.34 \mathrm{~g} / \mathrm{g}_{\text {cat }}$ in an earlier study with a similar test duration of $120 \mathrm{~min}$ (16). As shown in Fig. S7, methane conversion and total hydrogen yield decrease substantially beyond the initial 20 min to values of $41 \%$ and $36 \%$ after $120 \mathrm{~min}$. We attribute the long-term decrease in process efficiency to increased flow resistance in the central region due to decreasing porosity caused by highly enlarged and coalesced microfibers (see Fig. S10) that increase flow bypass through annular regions. We note that the issue of increased flow resistance could be readily addressed by adopting a roll-to-roll process that exploits the carbon felt's mechanical flexibility (34). We further emphasize that, as a result of the localized heated reaction region on the carbon felt, no carbon deposition occurred on the quartz window and or the reactor walls over the duration of testing; these issues have been common challenges in prior solar methane decomposition studies $(10,35,36)$. To assess the influence of the starting substrate, a methane decomposition test was also performed using an alumina/silica ceramic cloth under the same experimental conditions for $20 \mathrm{~min}$. The results are nearly identical to those with the carbon felt in terms of methane conversion (75\%) and hydrogen yield (71\%) (see Fig. S8). This result suggests that the present methane decomposition process can be expanded to other porous starting substrates to yield similar performance.

The process reported here offers many potential advantages over existing approaches to solar hydrogen production. For example, a prior study that used solar heating for SMR required the use of specialized catalysts to achieve "fuel conversion at reasonable rates" (37). However, the resulting catalyst and support introduce additional costs, complexity, and durability 
limits related to sintering and catalyst deactivation from solid carbon deposition. The present approach circumvents these limitations, as the deposited carbon itself serves both as catalyst and value-added product. SMR does offer an intrinsic advantage in producing one more mole of hydrogen per reactant mole of methane molecule than pyrolysis, but this benefit comes with the cost of higher heat input, $\Delta H_{S M R}^{o}=206 \mathrm{~kJ} / \mathrm{mol}$ (2). Using hydrogen's lower heat value of $-242 \mathrm{~kJ} / \mathrm{mol}$, at least $54 \%$ of the additional hydrogen from SMR would be recycled for process reaction heat.

According to a 2017 study (2), the global market for graphite, primarily for Li-ion batteries and steel production, is approximately 2 million metric tonnes (MMT). Based on the stoichiometric ratio of carbon to hydrogen in methane, these markets could potentially be served by the present process while producing approximately $0.67 \mathrm{MMT}$ of $\mathrm{H}_{2}$ annually. For scale context, the annual production of natural gas in the US is approximately 30 trillion cu.ft., or 616 MMT (2). The carbon content of this annual production is 462 MMT, with a corresponding 154 MMT of hydrogen. Therefore, applying the solar process described here to only a minute fraction $(<0.5 \%)$ of US-produced natural gas could satisfy the entire global graphite market while also providing clean hydrogen fuel.

Moreover, challenges related to intermittency of renewable energy sources are at least in part ameliorated by their intensive capture during peak insolation, e.g., via concentrating solar power systems (27), to create fuels that serve both as storage media and eventual power sources (38). We are optimistic that the process reported here can be readily engineered into such systems at practical scales and efficiencies to ameliorate the climate challenge by adapting the approach to a range of uses, from partial conversion of natural gas for blended hydrogen transmission (39), to zero-carbon full conversion, or even to negative-carbon with renewably sourced biogas feedstocks, all while co-producing high-value graphitic solids.

\section{References}

1. C. Figueres, et al., Nature 546, 593 (2017).

2. R. A. Dagle, et al., An Overview of Natural Gas Conversion Technologies for CoProduction of Hydrogen and Value-Added Solid Carbon Products, Tech. rep., Pacific Northwest National Laboratory (PNNL), Richland, WA (United States) (2017).

3. N. M. Haegel, et al., Science 364, 836 (2019). 
4. J. K. Dahl, et al., Energy 29, 715 (2004).

5. J. Jia, et al., Nature Communications 7, 13237 (2016).

6. W. C. Chueh, et al., Science 330, 1797 (2010).

7. T. Pregger, et al., International Journal of Hydrogen Energy 34, 4256 (2009).

8. J. A. Manion, Journal of Physical and Chemical Reference Data 31, 123 (2002).

9. J. Yeheskel, M. Epstein, Carbon 49, 4695 (2011).

10. S. Rodat, S. Abanades, J.-L. Sans, G. Flamant, International Journal of Hydrogen Energy 35, 7748 (2010).

11. S. Rodat, et al., Carbon 49, 3084 (2011).

12. D. Hirsch, A. Steinfeld, International Journal of Hydrogen Energy 29, 47 (2004).

13. G. Maag, G. Zanganeh, A. Steinfeld, International Journal of Hydrogen Energy 34, 7676 (2009).

14. S. Abanades, H. Kimura, H. Otsuka, International Journal of Hydrogen Energy 39, 18770 (2014).

15. M. Msheik, S. Rodat, S. Abanades, Energies 14, 3107 (2021).

16. J. Pinilla, et al., International Journal of Hydrogen Energy 37, 9645 (2012).

17. J. Peters, M. Weil, Resources 5, 46 (2016).

18. B. Hu, B. Li, R. Zhao, T. Yang, Review of Scientific Instruments 82, 065104 (2011).

19. D. Learn, P. Forbes, C. Sambuco, A Comprehensive Guide to Toxicology in Nonclinical Drug Development pp. 585-614 (2017).

20. M. Abuseada, N. Ozalp, Solar Energy 211, 700 (2020).

21. C. Ophoff, N. Ozalp, D. Moens, Applied Thermal Engineering 180, 115785 (2020).

22. A. Kogan, M. Kogan, J. Sol. Energy Eng. 124, 206 (2002). 
23. M. Abuseada, N. Ozalp, Solar Energy 197, 396 (2020).

24. C. Wei, K. K. Schwarm, D. I. Pineda, R. M. Spearrin, Optics Letters 45, 2447 (2020).

25. K. K. Schwarm, C. Wei, D. I. Pineda, R. Mitchell Spearrin, Applied Optics 58, 5656 (2019).

26. R. Buck, J. F. Muir, R. E. Hogan, Solar Energy Materials 24, 449 (1991).

27. M. Roeb, H. Muller-Steinhagen, Science 329, 773 (2010).

28. U. Mogera, R. Dhanya, R. Pujar, C. Narayana, G. U. Kulkarni, The Journal of Physical Chemistry Letters 6, 4437 (2015).

29. S. Stoft, Power System Economics (IEEE, 2002).

30. Y. Zhang, et al., Materials Research Express 7, 015609 (2020).

31. S. Bammidipati, G. D. Stewart, J. R. Elliott, S. A. Gokoglu, M. J. Purdy, AIChE Journal 42, 3123 (1996).

32. L. Zhou, et al., Science 362, 69 (2018).

33. M. B. Lundeberg, et al., Science 357, 187 (2017).

34. K. R. Saviers, M. A. Alrefae, T. S. Fisher, Advanced Engineering Materials 20, 1800004 (2018).

35. A. Abánades, et al., International Journal of Hydrogen Energy 36, 12877 (2011).

36. S. Rodat, S. Abanades, G. Flamant, Solar Energy 85, 645 (2011).

37. E. J. Sheu, E. M. Mokheimer, A. F. Ghoniem, International Journal of Hydrogen Energy 40, 12929 (2015).

38. Z. Abdin, et al., Renewable and Sustainable Energy Reviews 120, 109620 (2020).

39. J. Ogden, A. M. Jaffe, D. Scheitrum, Z. McDonald, M. Miller, Energy Policy 115, 317 (2018).

40. S. Brunauer, P. H. Emmett, E. Teller, Journal of the American Chemical Society 60, 309 (1938). 
41. X. Guo, et al., Science 344, 616 (2014).

42. D. C. Upham, et al., Science 358, 917 (2017).

\section{Acknowledgments}

The authors thank Abdalla Alghfeli for his contribution in co-building the simulated solar source and laboratory general instrumentation. TSF and MA thank Prof. Nesrin Özalp for helpful discussions related to simulated solar sources, and Prof. Robert Palumbo for use of the heat flux gauge and target used for characterizing the solar simulator's output. RMS and CW thank Prof. Daniel I. Pineda for helpful discussion related to chemical kinetics and Cantera. Funding: The authors thank the California NanoSystems Institute at UCLA and its Noble Family Innovation Fund for support of this work. Author contributions: Mostafa Abuseada: Conceptualization, Methodology, Software, Formal Analysis, Writing- Original Draft, Writing- Review \& Editing, Visualization; Chиуи Wei: Methodology, Software, Formal Analysis, Writing- Original Draft, Writing- Review \& Editing, Visualization; Mitchell Spearrin: Methodology, Supervision, Writing- Original Draft, Writing- Review \& Editing, Funding Acquisition; Timothy Fisher: Conceptualization, Methodology, Supervision, Writing- Original Draft, Writing- Review \& Editing, Funding Acquisition. Competing interests: The authors have no competing interests. Data and materials availability: All data, code, and materials used in the analysis are available to any researcher for purposes of reproducing or extending the analysis. Raw data from graphs is available as a supplementary file. 


\section{Supplementary Materials}

\section{Materials and Methods}

\section{Heat Flux and Temperature Distributions}

The heat flux distribution from the single-lamp high-flux solar simulator (HFSS) follows a Lorentzian distribution based on prior work and the nature of the ellipsoidal concentrator (43). In this work, the irradiation output from the HFSS was characterized and measured at discrete points using a Gardon type heat flux gauge (Vatell Corporation, TG1000-0) with a linear output voltage of $0-10 \mathrm{mV}$ corresponding to flux measurements up to $5 \mathrm{MW} / \mathrm{m}^{2}$. This heat flux gauge has an active gauge area equal to $1 \mathrm{~mm}$, and has been previously employed in prior work for HFSS characterization (44-46). To map the flux distribution at the focal plane, the gauge was mounted to and insulated from a water-cooled target to minimize thermal conduction between the gauge and target. Fig. S1a shows the experimental setup for characterizing the radiative output of the HFSS. In addition to its Lorentzian profile, the normalized distribution remains similar under varying operating currents supplied to the bulb; only the output magnitude changes linearly (43). This behavior has also been verified here, where a linear relationship between the supplied current and HFSS output is observed. The heat flux measurements at the focal plane of the HFSS with a current supply of $160 \mathrm{~A}$ are shown in Fig. $\mathrm{S1}$ b. The reported uncertainty of heat flux measurements is a contribution of manufacturer's calibration uncertainty $( \pm 3 \%)$, data acquisition accuracy $( \pm 2 \mu \mathrm{V})$, and standard deviation of averaged measurements, resulting in a typical total uncertainty of $\pm 4 \%$.

The radiative heat flux distribution at a given supply current, $I$, can be calculated using the Lorentzian profile (also shown in Fig. S1):

$$
q_{s}^{\prime \prime}(r, I)=\frac{A_{\text {solar }}(I)}{\pi} \frac{\sigma_{\text {solar }}}{\sigma_{\text {solar }}^{2}+r^{2}}
$$

with $\sigma_{\text {solar }}=0.00864 \mathrm{~m}$ and $A_{\text {solar }}=0.8189 I-38.88 \mathrm{~kW} / \mathrm{m}$, where $I$ is the current supplied to the HFSS. At an operating current of $160 \mathrm{~A}$, the value of $A_{\text {solar }}$ is $92.1 \mathrm{~kW} / \mathrm{m}$. Regardless of the current supplied and peak heat flux, the full width at half maximum (FWHM) represents the most concentrated region and equals $2 \sigma_{\text {solar }}(1.7 \mathrm{~cm})$.

For temperature measurements, the IR camera used was factory calibrated to a maximum temperature of $2100{ }^{\circ} \mathrm{C}$ with a manufacturer's estimated uncertainty of $\pm 2 \%$, or $\pm 25 \mathrm{~K}$ in the temperature range reported here. In our independent calibration of the device using a reference 
temperature transducer, the temperature uncertainty was estimated to be $\pm 22 \mathrm{~K}$ at a maximum temperature of $1550 \mathrm{~K}$.

\section{Carbon Felt Composition, Pre-treatment, and Analysis}

The carbon felt can be approximated as a regular array of carbon fibers. The fiber diameters in the $\mathrm{C} 100$ carbon felt are approx. $D=10 \mu \mathrm{m}$, and the effective density of the $\mathrm{C} 100$ felt can be calculated from the manufacturer's specifications for areal density $\left(285 \mathrm{~g} \mathrm{~m}^{-2}\right)$ and thickness (3.2 mm):

$$
\rho_{C 100}=\frac{\text { Areal Weight }}{\text { Thickness }}=\frac{285}{0.0032} \mathrm{~g} \mathrm{~m}^{-3}=89 \mathrm{~kg} \mathrm{~m}^{-3}
$$

The C100 felt is made from PAN (polyacrylonitrile) fibers, whose solid density falls in the range of 1.75 to $1.93 \mathrm{~g} / \mathrm{cm}^{3}$ (47). Here, we adopt the average value of $1.84 \mathrm{~g} / \mathrm{cm}^{3}\left(1840 \mathrm{~kg} / \mathrm{m}^{3}\right)$. Moreover, we assume initially that the conformal pyrolysis growth product maintains this solid density. Given the foregoing metrics and assumptions, the solid volume fraction of the C100 felt is:

$$
\psi_{C 100}=\frac{89 \mathrm{~kg} \mathrm{~m}^{-3}}{1840 \mathrm{~kg} \mathrm{~m}^{-3}}=0.0484
$$

This volume fraction provides a basis for calculating the average fiber pitch $(P)$ in $\mathrm{C} 100$ felt:

$$
P^{2}=\frac{1}{0.0484} \frac{\pi D^{2}}{4} \rightarrow P=4.03 D=40.3 \mu \mathrm{m}
$$

At this average pitch, the number of rows of fibers through the thickness of the felt is $N=79$.

Prior to methane decomposition, the carbon felt was pre-treated under the same thermal power and distribution from the HFSS, and for a duration of approximately $20 \mathrm{~min}$ in a vacuum environment. The main motivation for the thermal pre-treatment is to purify the felt from volatiles and trapped air to obtain more accurate weight measurements of the felt before and after processing to determine the total mass of carbon produced and captured. Upon the thermal pre-treatment, the carbon felt loses approx. $3 \%$ of its original mass.

The carbon product obtained is characterized using different techniques to assess quality and morphology. Raman spectra were obtained using a custom-built spectrometer that uses a $532 \mathrm{~nm}$ laser with a 40x achromat objective lens and a visible-light CCD detector in a Horiba iHR 550 imaging spectrometer. SEM images were obtained to assess morphology using a ZEISS Suppra 40VP field emission scanning electron microscope (SEM) and its secondary electron (SE) detector. Surface area was measured using a high-performance adsorption surface characterization analyzer (Micromeritics 3 Flex) and $\mathrm{N}_{2}$ adsorption at $77 \mathrm{~K}$, where the surface 
area is quantified per Brunauer-Emmett-Teller (BET) method (40). Lattice structural properties of the product were obtained via x-ray diffraction (XRD) measurements using a Panalytical $X^{\prime}$ Pert Pro X-ray powder diffractometer equipped with a $\mathrm{Cu} \mathrm{K} \alpha$ source $\left(\lambda_{X R D}=1.54 \AA\right)$.

\section{Chemical Kinetics and Equilibrium}

Another important reference point in evaluating methane decomposition is the gas composition predicted by chemical kinetics and equilibrium theory. The equilibrium compositions (at constant temperature and pressure) of the gas mixture over a range of temperatures are determined by minimizing the Gibbs free energy, and can be calculated with an appropriate chemical model that includes a reaction set with relevant species and thermodynamic properties. Here, we use the open-source tool Cantera to calculate equilibrium with a chemical model (USC Mech II (48)) comprised of 111 species covering C1-C6 hydrocarbons. This chemical mechanism is commonly used for natural gas pyrolysis and combustion analysis. The equilibrium concentrations of important species along with the measured steady-state values are shown in Fig. S2. Notably, while measured $\mathrm{CH}_{4}$ and $\mathrm{C}_{2} \mathrm{H}_{4}$ concentrations agree relatively well with predicted values, the measured $\mathrm{C}_{2} \mathrm{H}_{6}$ concentration is 1-2 orders of magnitude higher than equilibrium. Additionally, heavier hydrocarbons (e.g., $\mathrm{C}_{4} \mathrm{H}_{2}, \mathrm{C}_{6} \mathrm{H}_{6}$ ) are predicted to form in nonnegligible amounts but no signals of those species were captured by mass spectroscopy (see Fig. S6).

In practice, the extent of reaction can be hindered from reaching equilibrium due to flow residence time and chemical kinetics. To account for such effects, a further kinetic analysis has been performed with a plug flow reactor model using Cantera. In this simplified model, an isothermal reactor is represented by a steady-state channel with a diameter of $6.9 \mathrm{~cm}$, an inlet methane flow rate of $100 \mathrm{sccm}$, pressure of 25 torr, and temperature of $1300 \mathrm{~K}$. Perpendicular to the flow direction, the gas is assumed to be completely homogeneous, and the composition of the gas is allowed to change only in the axial direction. All diffusion processes are neglected. Under these assumptions, the reactor is spatially discretized into 200 axially distributed volumes within a $5 \mathrm{~mm}$ domain, with each volume modeled as a steady-state well-stirred reactor with surface chemistry. For the gas phase reactions, USC Mech II with 784 elementary reactions (optimized for $\mathrm{H}_{2} / \mathrm{C} 1-\mathrm{C} 4$ hydrocarbon kinetics) is used to capture the methane pyrolysis reaction pathways $(31,50)$ from $\mathrm{C} 1$ to $\mathrm{C} 2$ hydrocarbons as shown in Eq. $\mathrm{S} 5$.

$$
\mathrm{CH}_{4} \stackrel{-\mathrm{H}}{\longrightarrow} \mathrm{CH}_{3} \stackrel{+\mathrm{CH}_{3}}{\longrightarrow} \mathrm{C}_{2} \mathrm{H}_{6} \stackrel{-\mathrm{H}}{\longrightarrow} \mathrm{C}_{2} \mathrm{H}_{5} \stackrel{-\mathrm{H}}{\longrightarrow} \mathrm{C}_{2} \mathrm{H}_{4} \stackrel{-\mathrm{H}}{\longrightarrow} \mathrm{C}_{2} \mathrm{H}_{3} \stackrel{-\mathrm{H}}{\longrightarrow} \mathrm{C}_{2} \mathrm{H}_{2}
$$

For the surface chemistry, a reduced mechanism with 5 reactions is used based on previous 
studies of carbon CVD/CVI processes under similar temperature and pressure conditions (50) as shown in Table $\mathbf{S 1}$.

The resulting species concentrations as functions of axial distance are shown in Fig. S3. Despite the simplifications of the plug flow reactor model, a significant improvement in the agreement between predicted and measured concentrations is observed within the carbon felt thickness $\left(3.2 \mathrm{~mm}\right.$ ). In addition, heavier hydrocarbons (e.g. $\mathrm{C}_{4} \mathrm{H}_{2}, \mathrm{C}_{6} \mathrm{H}_{6}$ ) are predicted to form later than $\mathrm{C} 1 / \mathrm{C} 2$ hydrocarbons. This result is consistent with the absence of heavier hydrocarbons in the mass spectrum measurements, suggesting that the process is kinetically limited. Future work will aim to develop higher fidelity models that can capture thermal non-uniformities along the reactor.

\section{Laser Absorption Spectroscopy}

Laser absorption spectroscopy (LAS) is an optical diagnostic technique well-suited for timeresolved and quantitative measurement of species and temperature. LAS is well detailed in prior literature (51), and therefore only a brief overview is presented here for reader convenience. Molecular absorption through a uniform gas medium is governed by the Beer-Lambert law:

$$
\alpha_{v}=-\ln \left(\frac{I_{t}}{I_{0}}\right)_{\nu}=\sum_{i} P x_{\mathrm{abs}} S_{i}(T) \varphi_{i}\left(\nu, T, P, x_{\mathrm{abs}}\right) L
$$

where $I_{t} / I_{o}$ is the ratio of experimentally measured transmitted and incident laser intensity at frequency $\nu\left[\mathrm{cm}^{-1}\right], \alpha_{\nu}$ is the spectral absorbance at that frequency, $P[\mathrm{~atm}]$ is the total pressure, $S_{i}(T)\left[\mathrm{cm}^{-2} / \mathrm{atm}\right]$ is the temperature-dependent linestrength of transition $i$ at temperature $T[\mathrm{~K}]$, $x_{\text {abs }}$ is the mole fraction of the absorbing molecule, $L[\mathrm{~cm}]$ is the path-length of the absorbing medium, and $\varphi_{i}[\mathrm{~cm}]$ is the spectral lineshape of transition $i$. For well-isolated transitions, the integrated absorbance area can be calculated by integrating over the spectral domain:

$$
A_{i}=\int_{-\infty}^{\infty} \alpha_{v} d \nu=P S_{i}(T) x_{\mathrm{abs}} L
$$

which eliminates the dependence on the lineshape function $\varphi_{i}$. The integration can be achieved in practice by fitting an assumed lineshape function to the measured spectrum. Assuming independent knowledge of pressure and temperature from direct measurements, absorbing species mole fractions $x_{a b s}$ can be accurately determined.

A mid-infrared LAS system was developed for on-line monitoring of various hydrocarbon species $\left(\mathrm{CH}_{4}, \mathrm{C}_{2} \mathrm{H}_{4}, \mathrm{C}_{2} \mathrm{H}_{6}\right)$ present in the conversion process, as shown in Fig. 2. Two 
continuous-wave distributed feedback (DFB) interband cascade lasers (ICLs) (nanoplus Nanosystems and Technologies $\mathrm{GmbH}$ ) were used to access the $\mathrm{R}(15)$ manifold of the $\nu_{3}$ band of $\mathrm{CH}_{4}$ as well as one $\mathrm{R}(14)$ transition of the $\nu_{9}$ band of $\mathrm{C}_{2} \mathrm{H}_{4}$ near $3166 \mathrm{~cm}^{-1}$ and the ${ }^{R} \mathrm{Q}_{3}$ line cluster of $\mathrm{C}_{2} \mathrm{H}_{6}$ at $2997 \mathrm{~cm}^{-1}$, respectively. The two laser beams were aligned concentrically using flat mirrors and a flip mirror as shown in Fig. 2. The manually flipped mirror alternates the laser beams that are focused onto the PV detector (VIGO System PVI-4TE-5) for one second of data collection every 15 seconds (or 6 seconds during the first 2 minutes to better resolve the initial transient period), yielding an overall 30-seconds time resolution for each species. The lasers are current-modulated to scan over wavelength at $1 \mathrm{kHz}$ to resolve the lineshapes of the spectral transitions and to minimize noise from mechanical vibrations of the reactor. The raw signals were averaged over the 1-second collection period. Example measured spectra of the target species are shown in Fig. $\mathrm{S} 4$.

For $\mathrm{CH}_{4}$ and $\mathrm{C}_{2} \mathrm{H}_{4}$ measurements, relatively isolated transitions are resolved as shown on the left side of Fig. $\mathrm{S} 4$. The measured absorbance spectra were least-squares fitted assuming two Voigt lineshapes for $\mathrm{CH}_{4}$ and $\mathrm{C}_{2} \mathrm{H}_{4}$, respectively. Absorbance areas $A_{i}$ and collisional width $\nu_{c}$ were free parameters in the fitting process, and the Doppler width $\nu_{d}$ was calculated using temperatures from thermocouple measurements. Mole fractions for each species were then determined from Eq. S7. However, for $\mathrm{C}_{2} \mathrm{H}_{6}$ measurements, rovibrational transitions are numerous and blended such that spectra appear as a continuum rather than discrete transitions. In this case, the measured spectra were least-squares fitted with mole fraction $x_{a b s}$ directly as the free parameters, using the spectra parameters provided by Harrison et. al (52) to model the blended features. The final fractional residual (residual/maximum absorbance) from the Voigt fits of each line cluster was typically less than $2 \%$ for all transitions, confirming the general accuracy of the spectral models.

Additionally, we follow the Taylor series method (TSM) of uncertainty propagation (53) based on Eq. S7 to calculate the total uncertainty in measured mole fractions:

$$
\left(\frac{\Delta X_{\mathrm{abs}}}{X_{\mathrm{abs}}}\right)^{2}=\left(\frac{\Delta A_{\mathrm{abs}}}{A_{\mathrm{abs}}}\right)^{2}+\left(\frac{\Delta P_{\text {meas }}}{P_{\text {meas }}}\right)^{2}+\left(\frac{\Delta S_{j}(T)}{S_{j}(T)}\right)^{2}
$$

which includes the 1- $\sigma$ precision of the measured absorption over the 1-second collection period, a pressure uncertainty of $0.5 \%$ from the capacitance manometer, and linestrength uncertainty from the spectroscopic databases. Representative uncertainties for measured $\mathrm{CH}_{4}, \mathrm{C}_{2} \mathrm{H}_{4}$, and $\mathrm{C}_{2} \mathrm{H}_{6}$ mole fractions are listed in Table $\mathrm{S} 2$ 


\section{On-line Mass Spectroscopy}

A compact, high-resolution residual gas analyzer (RGA) was installed as an in situ mass spectrometer (MS) for further identification and quantification of the product stream composition. The RGA (INFICON, model \# TSPTT200) consists of an ionizer, a quadrupole mass filter, and 0-200 AMU Faraday Cup detector with an electron multiplier (EM), which enhances peak amplitude and position stability. Because the RGA needs to operate below pressures of approx. 1 $\mathrm{x} 10^{-3} \mathrm{~Pa}$, a suitable configuration must be developed to enable continuous sampling from significantly higher pressures while ensuring that the pressure within the RGA chamber remains below the maximum acceptable limit. Consequently, an adjustable leak valve (Kurt Lesker, model \# VZMD9538) was attached to the reactor's outlet stream, while the RGA compartment was supported with a turbomolecular pump (BOC Edwards, model \# EXT255H/100CF) and a backing rotary vane pump (Edwards, model \# RV3). This setup allows pressure maintenance of approx. $1 \times 10^{-5} \mathrm{~Pa}$ within the MS chamber. A leak valve was adjusted to control sampling from the reactor product stream such that the MS pressure is maintained within the desired operating range. The arrangement (see Fig. S5) provides a response time to changes in the main outlet feed as fast as few seconds.

The MS was calibrated to provide relative quantitative results (mole fractions) using known gas stream compositions consisting of the three most expected and prominent product species of the methane decomposition process: $\mathrm{CH}_{4}, \mathrm{H}_{2}$, and $\mathrm{C}_{2} \mathrm{H}_{2}$. The gas stream composition was controlled using a calibrated mass flow rate controller for each species at conditions similar to those expected experimentally. Such a procedure also accounts for variations from species diffusion through the leak valve and into the RGA compartment. For the next two dominant species, $\mathrm{C}_{2} \mathrm{H}_{4}$ and $\mathrm{C}_{2} \mathrm{H}_{6}$, the MS was calibrated using the NIST database fragmentation factors (54) along with sensitivity factors obtained from fitting the MS results to the IR absorption spectroscopy results. This approach provides quantitatively satisfactory results because the mole fractions of $\mathrm{C}_{2} \mathrm{H}_{4}$ and $\mathrm{C}_{2} \mathrm{H}_{6}$ are approx. $0.5 \%$ or lower under various process conditions. The calibration and verification runs were conducted at different dates to average errors within MS intensity signal variability. Upon calibrating the MS, differences between reference mole fractions and measured values led to the following uncertainty estimates for different species based on their relative residuals: $\mathrm{H}_{2}= \pm 1.5 \%, \mathrm{CH}_{4}= \pm 2.7 \%, \mathrm{C}_{2} \mathrm{H}_{2}= \pm 4.2 \%, \mathrm{C}_{2} \mathrm{H}_{4}= \pm$ $28 \%$, and $\mathrm{C}_{2} \mathrm{H}_{6}= \pm 35 \%$. The relatively large uncertainty estimates in the latter two species are due to their very low concentrations within the product stream and resulting low signal-to-noise ratios. 


\section{Chemical Analysis: Conversion and Yield}

With the product stream composition (mole fractions) fully quantified using the MS, the process methane conversion $\left(\mathrm{X}_{\mathrm{CH} 4}\right)$, hydrogen yield $\left(Y_{\mathrm{H}_{2}}\right)$, and carbon yield $\left(Y_{\mathrm{C}}\right)$ can all be identified. The analysis considers only the five most dominant species in the product stream $(0.1 \%$ or higher), which are $\mathrm{H}_{2}, \mathrm{CH}_{4}, \mathrm{C}_{2} \mathrm{H}_{2}, \mathrm{C}_{2} \mathrm{H}_{4}$, and $\mathrm{C}_{2} \mathrm{H}_{6}$. By formulating a balance over the hydrogen atoms, the following relation ensues:

$$
2 \dot{n}_{C H_{4}, \text { in }}=\dot{n}_{\text {out }}\left(x_{H_{2}}+2 x_{C_{H_{4}}}+x_{C_{2} H_{2}}+2 x_{C_{2} H_{4}}+3 x_{C_{2} H_{6}}\right)
$$

Note that "out" has been omitted from the mole fractions of the product stream for brevity (no mole fractions are needed for the single-species inlet stream). Rearranging Eq. S9, we derive an expression to quantify the total molar flow rate out as:

$$
\dot{n}_{\text {out }}=\frac{2 \dot{n}_{\mathrm{CH}_{4}, \text { in }}}{x_{\mathrm{H}_{2}}+2 x_{\mathrm{CH}_{4}}+x_{\mathrm{C}_{2} \mathrm{H}_{2}}+2 x_{\mathrm{C}_{2} \mathrm{H}_{4}}+3 x_{C_{2} \mathrm{H}_{6}}}
$$

Upon obtaining the outlet molar flow rate, the methane conversion, defined as the relative difference between inlet and outlet methane flow rates, can be calculated as:

$$
X_{\mathrm{CH}_{4}}=\frac{\dot{n}_{\mathrm{CH}_{4}, \text { in }}-\dot{n}_{\text {out }} x_{C H_{4}}}{\dot{n}_{\mathrm{CH}, \text { in }}}
$$

Similarly, the overall hydrogen yield, defined as the fraction of all inlet hydrogen that emerges as hydrogen gas in the product stream, can be quantified as:

$$
Y_{H_{2}}=\frac{\dot{n}_{\text {out }} x_{H_{2}}}{2 \dot{n}_{C H_{4}, i n}}
$$

Then, by formulating a balance over the carbon atoms, the rate of carbon mass deposition can be quantified as:

$$
\dot{m}_{C}=\left[\dot{n}_{C H_{4}, \text { in }}-\dot{n}_{\text {out }}\left(x_{C H_{4}}+2 x_{C_{2} H_{2}}+2 x_{C_{2} H_{4}}+2 x_{C_{2} H_{6}}\right)\right] M_{C}
$$

In a similar manner to the total hydrogen yield, the total carbon yield can be obtained using:

$$
Y_{C}=\frac{\dot{m}_{C}}{M_{C} \dot{n}_{C H_{4}, i n}}
$$

Following the foregoing quantitative approach, real-time process monitoring results from the MS for methane decomposition through the carbon felt at a flow rate of $100 \mathrm{sccm}$, pressure of 25 Torr, gross radiant power of $2.24 \mathrm{~kW}$ (160 A HFSS current), and a total decomposition 
period of 20 min are shown in Fig. S6. The steady-state methane conversion, hydrogen yield, and carbon yield for these conditions are calculated to be $73.1 \% \pm 0.9 \%, 68.7 \% \pm 1.2 \%$, and $58.3 \% \pm 1.8 \%$. Despite the large uncertainty estimates of secondary byproducts monitored via the MS, measurement uncertainties associated with conversion and yield parameters are low. The net carbon weight collected on the carbon felt was $0.62 \mathrm{~g} \pm 0.005 \mathrm{~g}$.

To assess methane decomposition performance over time, a longer duration experimental test was conducted under the standard testing conditions but for a total decomposition period of $120 \mathrm{~min}$. The process monitoring results are shown in Fig. S7. The results indicate a relatively consistent behavior initially, but over long times, the methane conversion and related hydrogen yield decrease. We attribute this decrease to the growth of carbon fiber diameters in the central region of the felt, causing higher flow resistance and greater flow bypass through lower-temperature regions of the felt (see Fig. S10 below).

To assess the effect of the starting material (carbon felt), the methane decomposition process was tested using an alumina/silica wool (Morgan Advanced Materials, Cerablanket). The ceramic fiber wool consists of $46 \%$ alumina and $54 \%$ silica by weight. The ceramic cloth was of the same dimensions as the carbon felt (diameter of $6.9 \mathrm{~cm}$ and thickness of $3.2 \mathrm{~mm}$ ); however, the ceramic cloth's different fiber diameter and porosity could potentially contribute to changes in performance. Despite the significantly different starting substrate, the process results are very similar as shown in Fig. S8. The steady-state methane conversion, hydrogen yield, and carbon yield for the aforementioned conditions are estimated to be $74.6 \% \pm 1.0 \%, 71.1 \% \pm 1.1 \%$, and $64.0 \% \pm 1.8 \%$.

\section{SEM Images}

A ZEISS Supra 40VP filed emission scanning electron microscope (SEM) with a high-efficiency In-lens, and secondary electron (SE) and backscattered electron (BSE) detectors was used for SEM imaging. The carbon felt samples possess sufficient conductivity and allow for SEM images to be taken using the SE detector without other sample preparation steps (e.g., coating). To quantify the growth of the carbon felt fibers and hence their diameters, SEM images were obtained at radial increments of $2.5 \mathrm{~mm}$ starting from the center of the cylindrical felt to up to a radial distance of $25 \mathrm{~mm}$. Representative SEM images are shown in Fig. S9.

Additionally, an image of the central region of the carbon felt after a two-hour test is shown in Fig. S10. The SEM image reveals that after long methane decomposition and carbon deposition, the fibers grow much larger in size and coalesce to the point that the flow is highly 
restricted in the central region as compared to the annular region.

\section{Surface Area Characterization}

Specific surface areas of the carbon felt before and after $\mathrm{CH}_{4}$ decomposition were analyzed using a high-performance adsorption surface characterization analyzer (Micromeritics 3Flex). All samples analyzed were pre-treated and outgassed at $250{ }^{\circ} \mathrm{C}$ to remove volatile impurities that might affect surface area measurements. Then, using nitrogen gas adsorption at $77 \mathrm{~K}$, the surface areas of different samples were quantified based on the Brunauer-Emmett-Teller (BET) method (40).

BET surface characterization results are summarized in Table S3, in which the sample mass after outgassing is indicated, and the BET range used for the surface area quantification corresponds to relative pressures $\left(P / P^{o}\right)$ of $0.1-0.3$. Although the BET correlation is below 0.999, the primary purpose of this characterization was to compare the relative surface area of the original carbon felt to that containing the carbon product through methane decomposition. Through such a comparison, the nature of the carbon product deposited can be determined. The BET plots obtained for the carbon product in the central region $(0-5 \mathrm{~mm})$ in addition to the original carbon felt are shown in Fig. S11

Using SEM results, the fiber diameters were determined to be 97, 69, and $20 \mu \mathrm{m}$ at 0,5 , and $10 \mathrm{~mm}$ from the center of the carbon felt product. These diameters compare to an initial fiber diameter of only $9.6 \mu \mathrm{m}$ in the carbon felt. Without considering microporosity, the specific surface area would correlate with area/volume ratio that is proportional to $1 / D_{f}$, where $D_{f}$ is the fiber diameter. Using the maximum and minimum diameters within each range $(0-5 \mathrm{~mm}$ and 5-10 $\mathrm{mm}$ ), the specific surface area would be expected to decrease by approx. 7-10 times for the 0-5 $\mathrm{mm}$ region and 2-7 times for the 5-10 mm region. However, the specific surface area instead increases by 5- and 2-fold. This result is a clear indication that the deposited carbon product has a significantly lower density and thus is porous in nature.

\section{X-ray Diffraction}

XRD measurements were obtained using a Panalytical X'Pert Pro X-ray powder diffractometer that is equipped with a $\mathrm{Cu} \mathrm{K} \alpha$ source $\left(\lambda_{X R D}=1.54 \AA\right)$ operating at $45 \mathrm{kV}$ and $40 \mathrm{~mA}$. The XRD scan ranges from $2 \theta$ of $5^{\circ}$ to $100^{\circ}$, with a step size of $0.017^{\circ}$. Running at a continuous scanning mode with a computer-controlled divergence slit size, the scan time was set to $11^{\circ} \mathrm{min}$. Structural quantitative parameters of the carbon material is determined using XRD measurements, 
shown in Fig. 5b, for the original carbon felt as compared to that with the carbon product. The portion of the sample with carbon deposition analyzed is only the central region with a diameter of $15 \mathrm{~mm}$, since this region showed significant carbon deposition. The average interplanar distance between the carbon layers, $d_{002}$, is determined from the (002) reflection position, $\theta_{002}$, using Bragg's law (56):

$$
d_{002}=\frac{\lambda_{X R D}}{2 \sin \theta_{002}}
$$

Additionally, using the full width at half maximum (FWHM) of the (002) reflection in radians, $\beta_{002}$, the average crystallite size along the c-axis, $L_{c, X R D}$, is determined using the Scherrer equation:

$$
L_{c, X R D}=\frac{0.9 \lambda_{X R D}}{\beta_{002} \cos \theta_{002}}
$$

Based on the XRD measurements obtained, $d_{002}$ is determined to be 3.56 and $3.42 \AA$ for the original carbon felt and that with the carbon product, while $L_{c, X R D}$ is 2.07 and $9.69 \mathrm{~nm}$, respectively.

\section{Deposition Rate and Gas Residence Time}

The deposition rate was estimated using the actual carbon mass collected on the carbon felt rather than the theoretical estimated mass (via carbon mass balance approach). By measuring the carbon mass before and after decomposition, the net carbon mass collected was $0.62 \mathrm{~g}$ for 20 min of methane decomposition at a flow rate of $100 \mathrm{sccm}$, pressure of 25 Torr, and gross radiant power of $2.24 \mathrm{~kW}$. Therefore, the nominal deposition rate as reported in the manuscript is estimated to be $620 \mathrm{mg} \div 20 / 60 \mathrm{hr}=1860 \mathrm{mg} / \mathrm{hr}$.

The gas residence time was estimated from the ratio of flow distance, $L$, to velocity, $v$, as:

$$
\tau_{\text {res }}=\frac{L}{v}=\frac{L \rho_{C H 4} \pi D^{2}}{4 \dot{m}_{C H_{4}}}
$$

The flow is assumed to be isothermal and isobaric at a temperature of $1000{ }^{\circ} \mathrm{C}$. The length of the reaction zone is $L=3.2 \mathrm{~mm}$, reactor diameter is $D=68.6 \mathrm{~mm}$, and the mass flow rate is $100 \mathrm{sccm}$. Using methane density $\left(\rho_{\mathrm{CH} 4}\right)$ under these conditions, the reaction zone residence time is estimated to be $54 \mathrm{~ms}$.

\section{Supplementary Text}

Thermal pyrolysis of methane has been demonstrated in prior work, including several studies that drive the reaction with concentrated solar power $(4,10,11,13,14,16,36)$. For example, 
indirect solar methane decomposition in a pilot-scale $50 \mathrm{~kW}$ tubular reactor was demonstrated in temperature range of 1608-1928 $\mathrm{K}$ at atmospheric pressure $(10,11)$. Methane conversion was $72 \%$ or higher, with significantly lower hydrogen yield (57-88\%) and much lower carbon yield (41-63\%). The carbon product was characterized as carbon black with a high D/G Raman peak ratios (the lower the ratio, the better the carbon quality). In an attempt to enhance heat transfer within the methane flow, a previous study investigated methane decomposition in a 5 $\mathrm{kW}$ carbon black particle-flow direct solar reactor (13) in the temperature range 1300-1600 K. Although direct solar reactors are significantly more efficient than indirect ones in terms of thermal losses, they can potentially suffer from carbon deposition on the reactor window that leads to local window heating and failure (15). Another study used indirect solar thermo-catalytic methane decomposition in a $1 \mathrm{~kW}$ (net) packed-bed reactor under a Gaussian flux distribution with a maximum insolance of $16 \mathrm{MW} / \mathrm{m}^{2}$ operating at temperatures of $1273-1523 \mathrm{~K}$ and atmospheric pressure (14). A carbon black catalyst was utilized in this study to lower operating temperatures and improve hydrogen and carbon yields. Their carbon product was also a carbon black but with a higher density than the catalyst used. Once the packed-bed catalyst was deactivated, it was combusted and replaced with fresh catalyst. Another study investigated direct solar catalytic decomposition of methane in a solar rotary bed reactor with carbon and metal-based catalysts (16). Although higher-quality carbon products and lower operating temperatures were obtained with metal-based catalysts, the use of carbon black catalyst produced an amorphous carbon product with no distinct XRD peaks. To obtain metal-free carbon, the authors suggested applying post-processing purification, with an unknown process power burden or loss in quality of high-quality carbon product.

In all previous work that used no catalysts or carbon-based catalysts, the solid product of $\mathrm{CH}_{4}$ decomposition has produced carbon black and hence amorphous structure. Another frequently observed issue is reactor clogging by solid carbon deposits. For example, experiments were terminated an hour into testing as a result of progressive tube clogging (10), and in another study the tubes were completely blocked in (35). In another study (36), the initial carbon in $\mathrm{CH}_{4}$ was distributed upon its decomposition as approximately $3 \%$ in unconverted $\mathrm{CH}_{4}, 50 \%$ in acetylene byproduct, $34 \%$ as carbon deposited in reactor tubes, and only $2 \%$ as captured solid carbon (36). Additionally in direct solar reactors, processes also suffer from carbon deposition on the reactor window $(13,15)$. This challenge has encouraged research work into other approaches, such as through the non-solar conversion of methane to hydrogen, ethylene, and aromatics to avoid solid carbon product (41) or the use of catalytic molten metals for the pro- 
duction of hydrogen and separable carbon product (42). However, these alternative approaches suffer further challenges, such as the production of carbon product with metal impurities (approximately $92 \%$ carbon content) with the use of molten metals.

The graphitic product of the solar methane decomposition process presented here is of distinctive quality compared to those reported in prior literature with no or carbon-based catalysts. From the Raman results in Fig. 5a, the intensity ratios of the D and G Raman peaks $\left(I_{D} / I_{G}\right)$ of the carbon product are 0.21 and 0.41 at the center and $5 \mathrm{~mm}$ radius, with distinct $2 \mathrm{D}$ peaks at both locations. This result compares to an $I_{D} / I_{G}$ ratio of approximately 1.6 and the absence of a $2 \mathrm{D}$ peak in a previous solar-thermal process (11). Additionally, the graphitic product is of much higher quality than amorphous carbon obtained in (16) and closer to their carbon nanofibers and nanotubes $\left(d_{002}=3.38 \AA\right.$ ) obtained from methane pyrolysis using metallic catalysts. However, many challenges exist for metallic catalysts, such as sintering, fast deactivation, and the need to separate the carbon product from the catalyst, where the deterioration of quality upon separation is unclear.

\section{Figures S1 to S11}
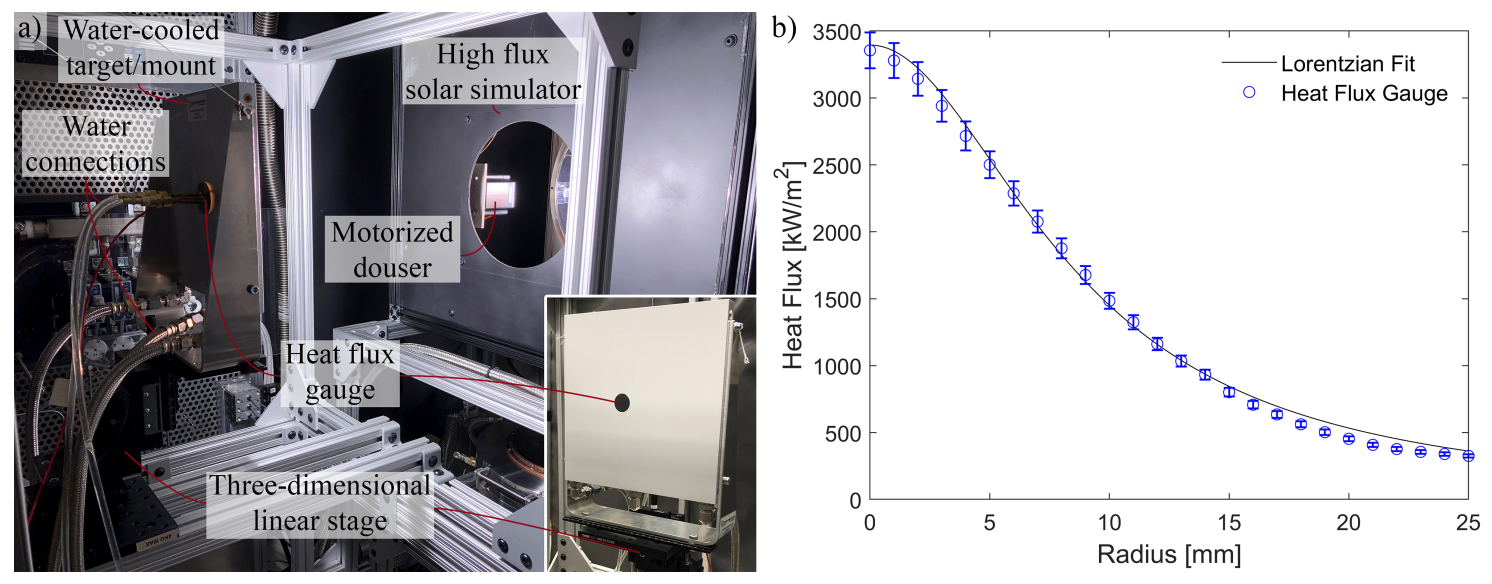

Figure S1: (a) Photograph of the experimental setup used in characterizing the output from the HFSS, and (b) heat flux distribution as measured using the heat flux gauge at the focal plane with 160 A supplied current along with the fitted Lorenztian distribution. 


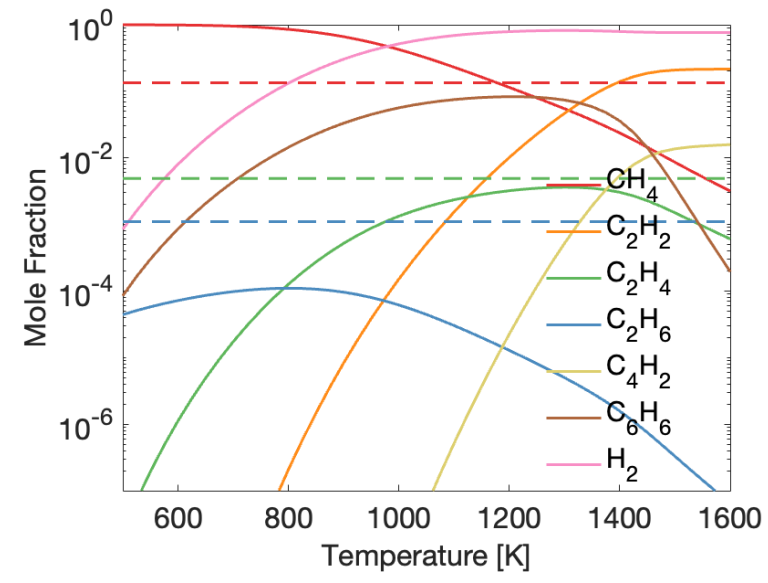

Figure S2: Equilibrium concentrations of important hydrocarbons over a range of temperatures. Dash lines indicate measured steady-state concentrations from IR absorption.

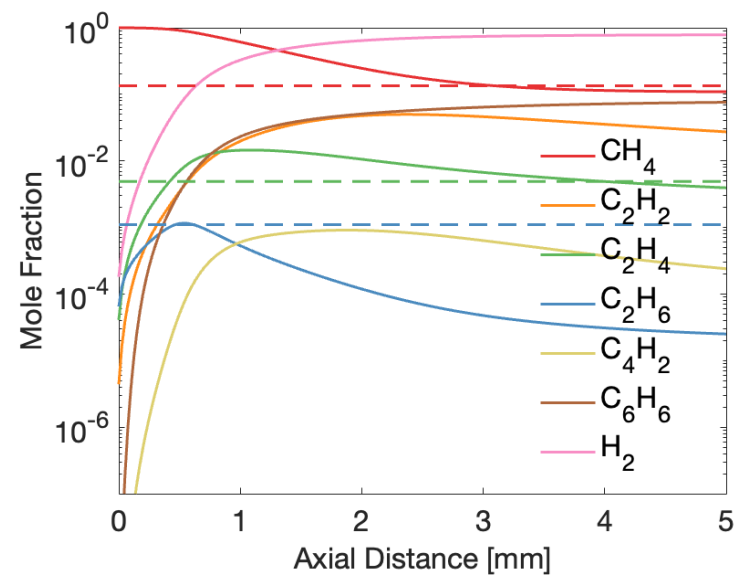

Figure S3: Evolution of species concentrations along the axial distance. Dashed lines indicate measured steady-state concentrations from IR absorption. 

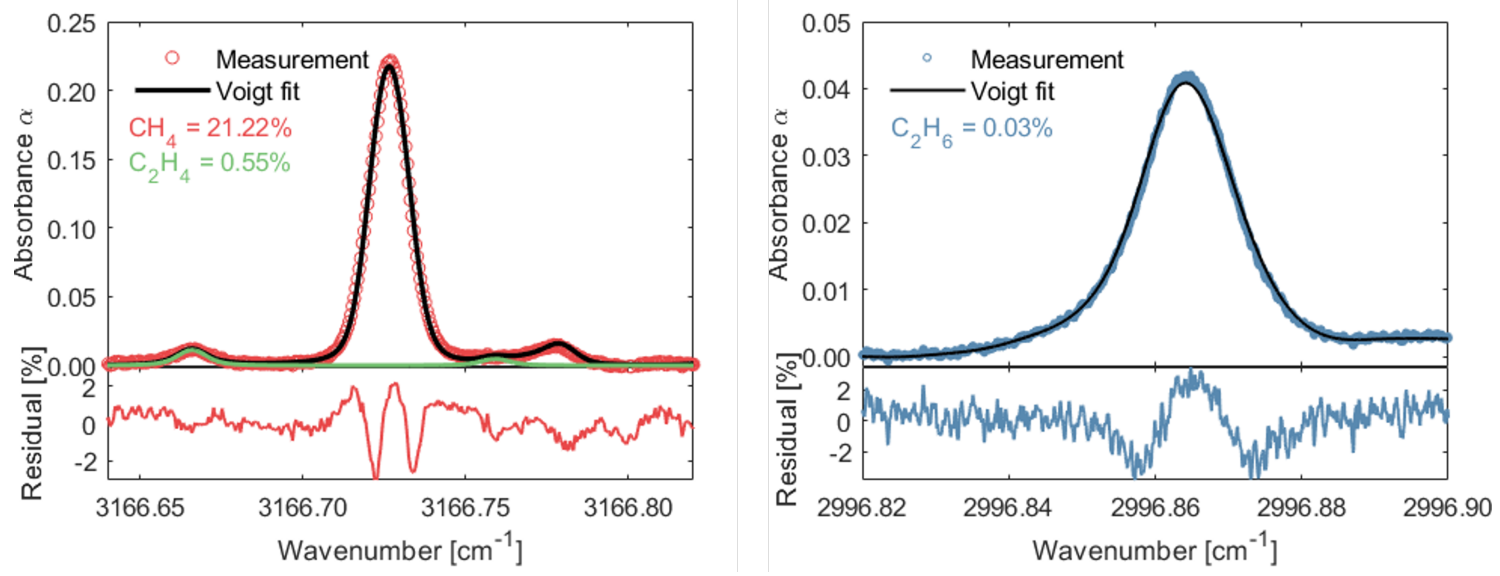

Figure S4: Example absorbance spectra and spectral fits of the $\mathrm{CH}_{4}, \mathrm{C}_{2} \mathrm{H}_{4}$ (left), and $\mathrm{C}_{2} \mathrm{H}_{6}$ (right) transitions.

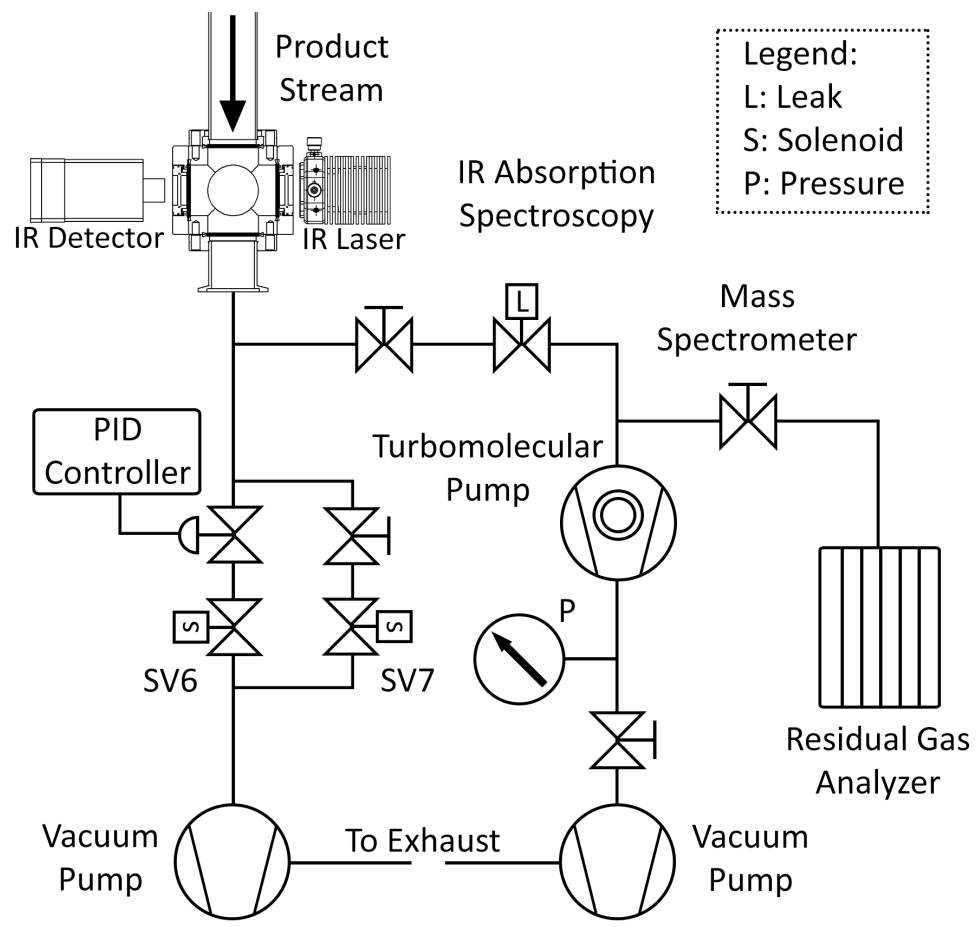

Figure S5: Schematic of the MS configuration and sampling from the reactor's main product stream. 

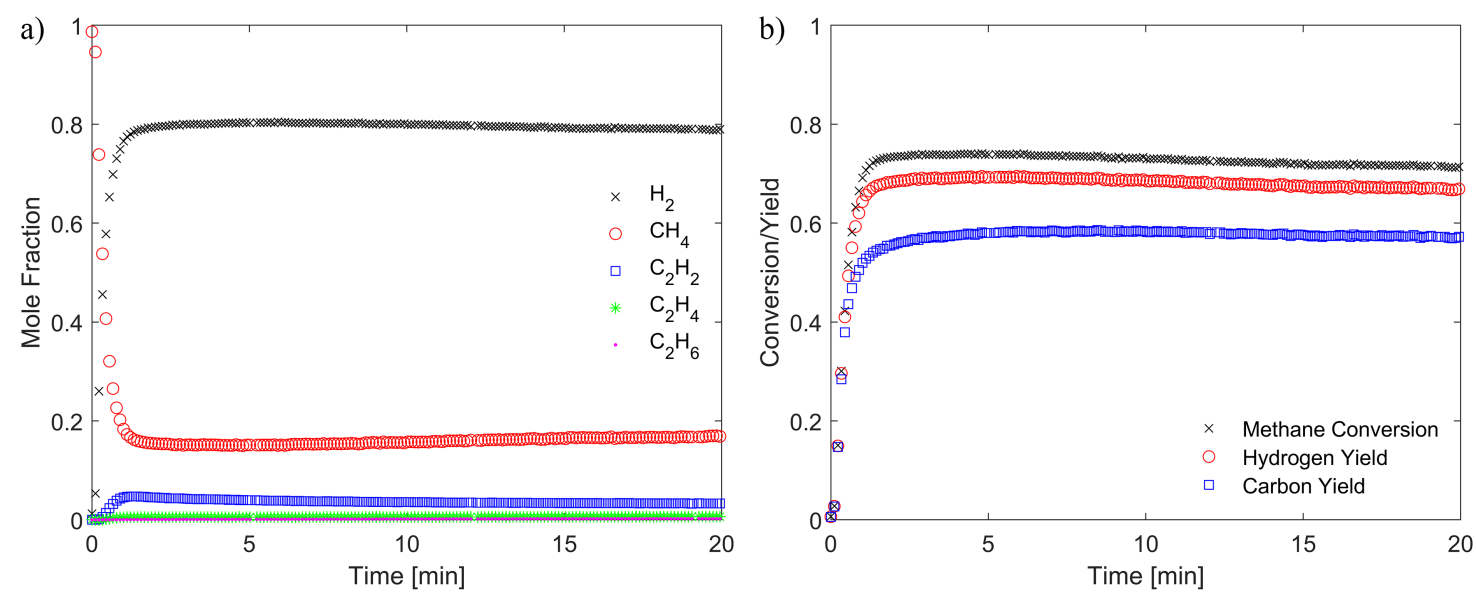

Figure S6: Real-time monitoring results from the calibrated mass spectrometer showing (a) mole fractions in the product stream, and (b) methane conversion and product yields for $\mathrm{CH}_{4}$ decomposition through carbon felt at $100 \mathrm{sccm}$ flow rate, 25 Torr pressure, $2.24 \mathrm{~kW}$ gross radiant power, and 20 min reaction period.
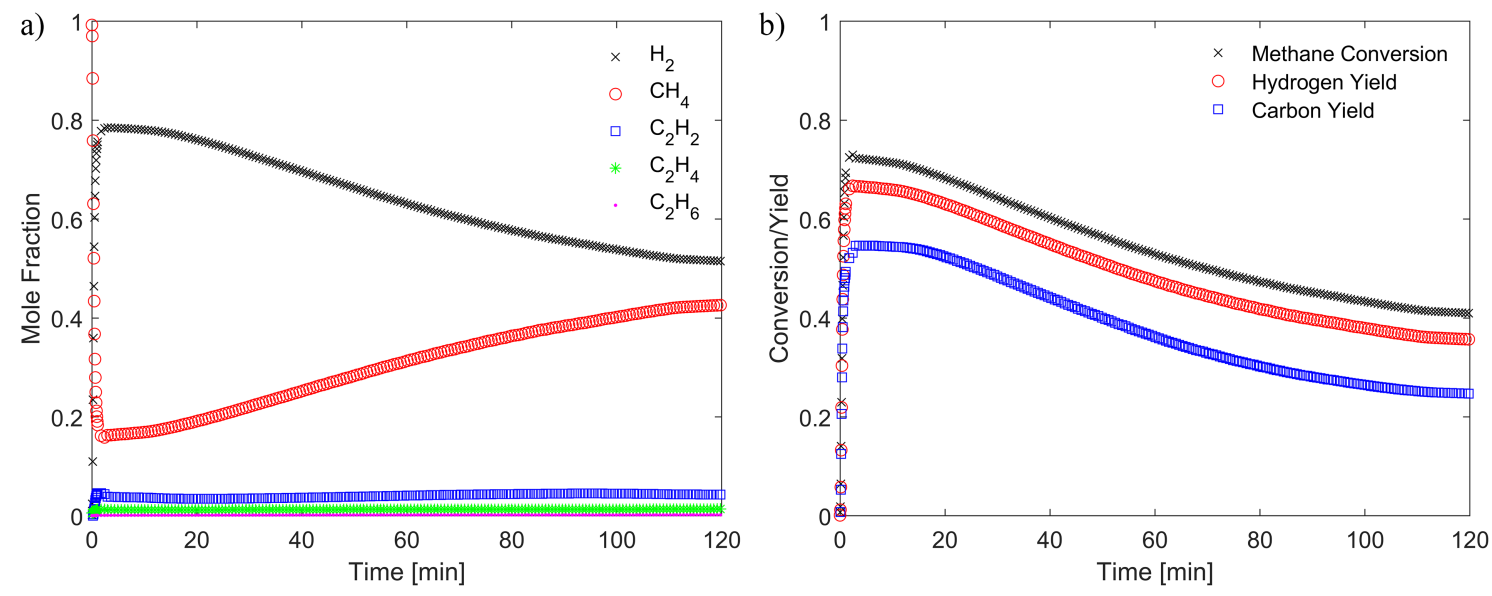

Figure S7: Real-time monitoring results from the calibrated mass spectrometer showing (a) mole fractions in the product stream, and (b) methane conversion and product yields for $\mathrm{CH}_{4}$ decomposition through carbon felt at $100 \mathrm{sccm}$ flow rate, 25 Torr pressure, $2.24 \mathrm{~kW}$ gross radiant power, and $120 \mathrm{~min}$ reaction period. 

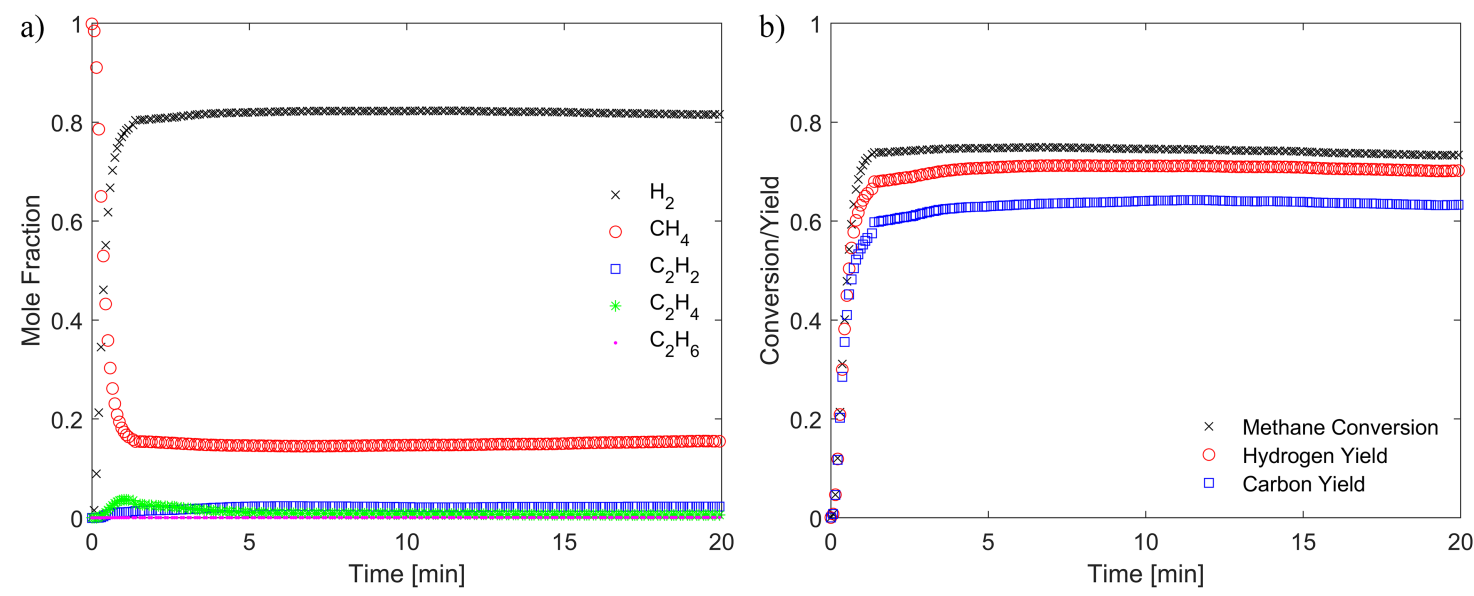

Figure S8: Real-time monitoring results from the calibrated mass spectrometer showing (a) mole fractions in the product stream, and (b) methane conversion and product yields for $\mathrm{CH}_{4}$ decomposition through ceramic felt at $100 \mathrm{sccm}$ flow rate, 25 Torr pressure, $2.24 \mathrm{~kW}$ gross radiant power, and 20 min reaction period.
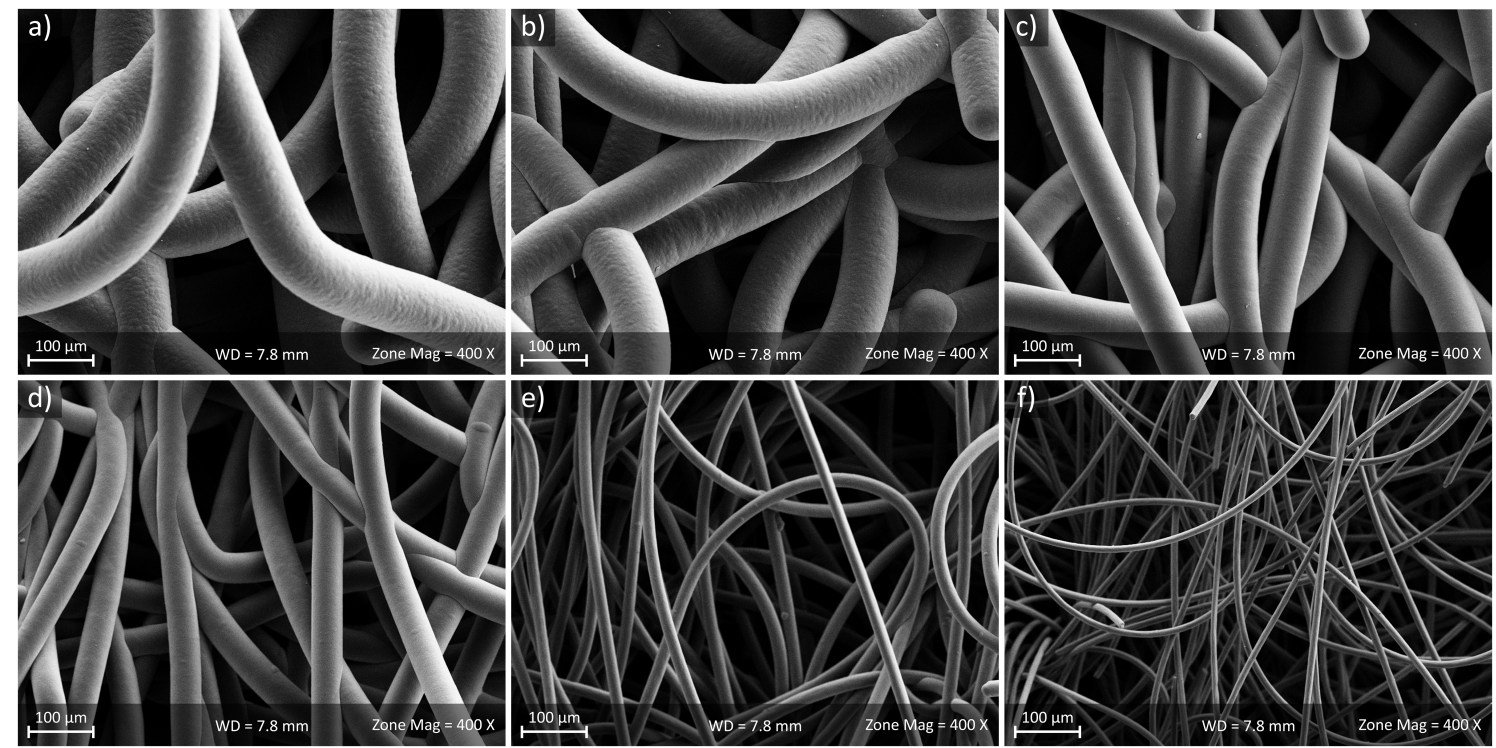

Figure S9: SEM images of the carbon felt after methane decomposition and carbon deposition at radial distances of (a) 0 , (b) 2.5, (c) 5, (d) 7.5, (e) 10, and (f) $12.5 \mathrm{~mm}$ from the center and under same magnification. $\mathrm{CH}_{4}$ decomposition at $100 \mathrm{sccm}$ flow rate, 25 Torr pressure, 2.24 $\mathrm{kW}$ gross radiant power, and 20 min reaction period. 


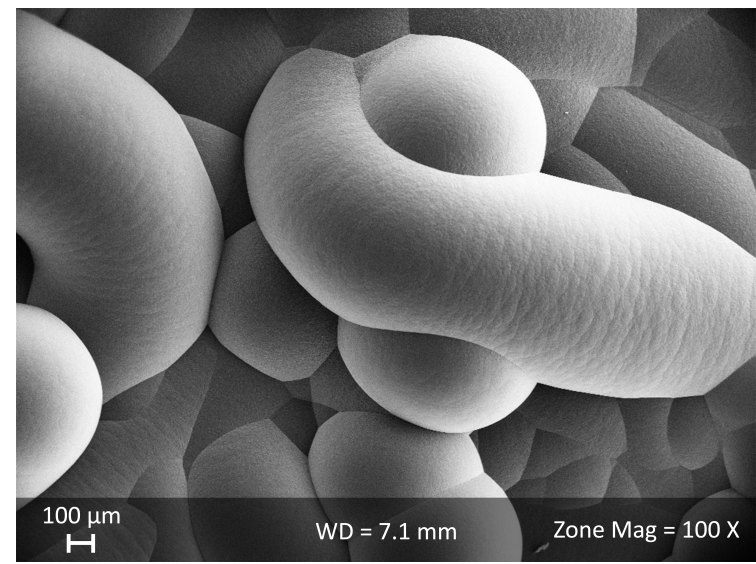

Figure S10: SEM image of the carbon felt's central region after $\mathrm{CH}_{4}$ decomposition and carbon deposition at $100 \mathrm{sccm}$ flow rate, 25 Torr pressure, $2.24 \mathrm{~kW}$ gross radiant power, and $120 \mathrm{~min}$ reaction period.
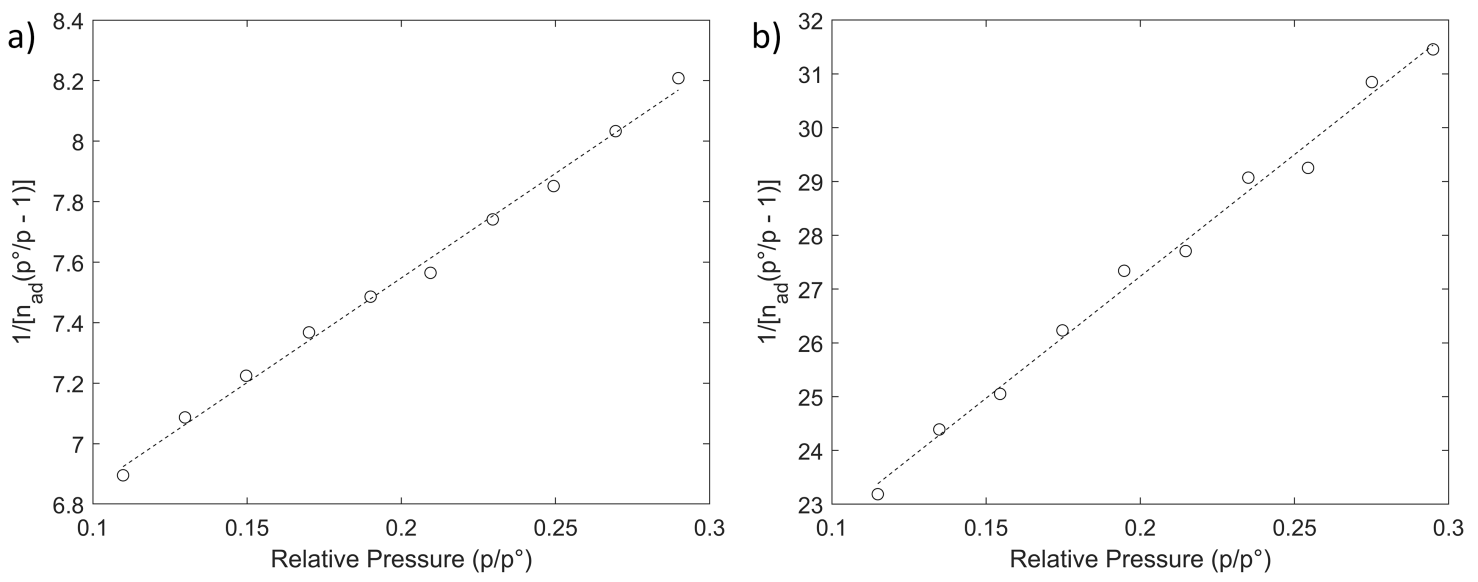

Figure S11: BET results for the (a) carbon product from $0-5 \mathrm{~mm}$ radius and (b) original carbon felt. 


\section{Tables S1 to S3}

Table S1: Surface mechanism for carbon deposition used in the plug flow reactor simulation.

1. $\mathrm{C}_{2} \mathrm{H}_{2}+2 \mathrm{C}(\mathrm{S}) \Rightarrow 2 \mathrm{C}(\mathrm{S})+2 \mathrm{C}(\mathrm{D})+\mathrm{H}_{2}$
2. $\mathrm{C}_{6} \mathrm{H}_{6}+6 \mathrm{C}(\mathrm{S}) \Rightarrow 6 \mathrm{C}(\mathrm{S})+6 \mathrm{C}(\mathrm{D})+3 \mathrm{H}_{2}$
3. $\mathrm{C}_{2} \mathrm{H}_{4}+2 \mathrm{C}(\mathrm{S}) \Rightarrow 2 \mathrm{C}(\mathrm{S})+2 \mathrm{C}(\mathrm{D})+2 \mathrm{H}_{2}$
4. $\mathrm{H}+\mathrm{CH}(\mathrm{S}) \Leftrightarrow \mathrm{C}(\mathrm{S})+\mathrm{H}_{2}$
5. $\mathrm{H}+\mathrm{C}(\mathrm{S}) \Leftrightarrow \mathrm{CH}(\mathrm{S})$

Table S2: Measurement uncertainties for LAS.

\begin{tabular}{cccc}
\hline Species & $1-\sigma$ & Linestrength uncertainties & Overall uncertainties \\
\hline $\mathrm{CH}_{4}$ & $2 \%$ & $5 \%$ & $5.4 \%$ \\
$\mathrm{C}_{2} \mathrm{H}_{4}$ & $12 \%$ & $10 \%$ & $15.6 \%$ \\
$\mathrm{C}_{2} \mathrm{H}_{6}$ & $3 \%$ & $4 \%$ & $5 \%$ \\
\hline
\end{tabular}

Table S3: Summary of BET results for $\mathrm{CH}_{4}$ decomposition at $100 \mathrm{sccm}$ flow rate, 25 Torr pressure, $2.24 \mathrm{~kW}$ gross radiant power, and 20 min reaction period.

\begin{tabular}{|l|l|l|l|l|}
\hline $\begin{array}{l}\text { Radius } \\
{[\mathrm{mm}]}\end{array}$ & $\begin{array}{l}\text { Sample mass } \\
{[\mathrm{mg}]}\end{array}$ & $\begin{array}{l}\text { BET specific surface } \\
\text { area }\left[\mathrm{m}^{2} / \mathrm{g}\right]\end{array}$ & $\begin{array}{l}\text { BET con- } \\
\text { stant }\end{array}$ & $\begin{array}{l}\text { Correlation } \\
\text { coefficient }\end{array}$ \\
\hline $0-5$ & 102 & $7.58 \pm 0.09$ & 2.07 & 0.997 \\
\hline $5-10$ & 137 & $3.03 \pm 0.09$ & 2.23 & 0.984 \\
\hline Original & 85 & $1.54 \pm 0.04$ & 3.49 & 0.996 \\
\hline
\end{tabular}




\section{Supplementary References}

43. M. Abuseada, C. Ophoff, N. Ozalp, Journal of Solar Energy Engineering 141, 1 (2019).

44. G. Levêque, R. Bader, W. Lipiński, S. Haussener, Optics Express 24, 1360 (2016).

45. F. Lei, et al., Chemical Engineering Journal 355, 58 (2019).

46. J. Sarwar, G. Georgakis, R. LaChance, N. Ozalp, Solar Energy 100, 179 (2014).

47. P. V. Gulgunje, et al., Carbon 95, 710 (2015).

48. H. Wang, et al., USC Mech Version II. High-Temperature Combustion Reaction Model of H2/CO/C1-C4 Compounds (2007).

49. S. Bammidipati, G. D. Stewart, J. R. Elliott, S. A. Gokoglu, M. J. Purdy, AIChE Journal 42, 3123 (1996).

50. N. Birakayala, E. A. Evans, Carbon 40, 675 (2002).

51. C. S. Goldenstein, R. M. Spearrin, J. B. Jeffries, R. K. Hanson, Progress in Energy and Combustion Science 60, 132 (2017).

52. J. J. Harrison, N. D. Allen, P. F. Bernath, Journal of Quantitative Spectroscopy and Radiative Transfer 111, 357 (2010).

53. C. Wei, D. I. Pineda, L. Paxton, F. N. Egolfopoulos, R. M. Spearrin, Applied Physics B 124, 123 (2018).

54. NIST Mass Spectrometry Data Center, W. E. Wallace, Director, NIST Standard Reference Database Number 69, P. Linstrom, W. Mallard, eds. (National Institute of Standards and Technology, Gaithersburg MD, 20899, 2011), chap. NIST Chemi.

55. S. Brunauer, P. H. Emmett, E. Teller, Journal of the American Chemical Society 60, 309 (1938).

56. M. Pawlyta, J.-N. Rouzaud, S. Duber, Carbon 84, 479 (2015). 


\section{Movie}

Movie S1: Video of methane decomposition products under periodic irradiation. Time response of (left) methane mole fraction in the product stream and (right) IR absorption spectrum during pulsed on/off exposure of the simulated solar concentrator at 1-minute intervals. Flow rate of $100 \mathrm{sccm}$, pressure of 25 Torr, gross peak radiant power of $2.24 \mathrm{~kW}$. 